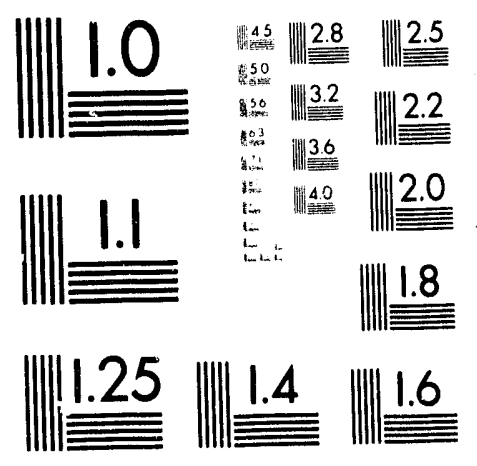



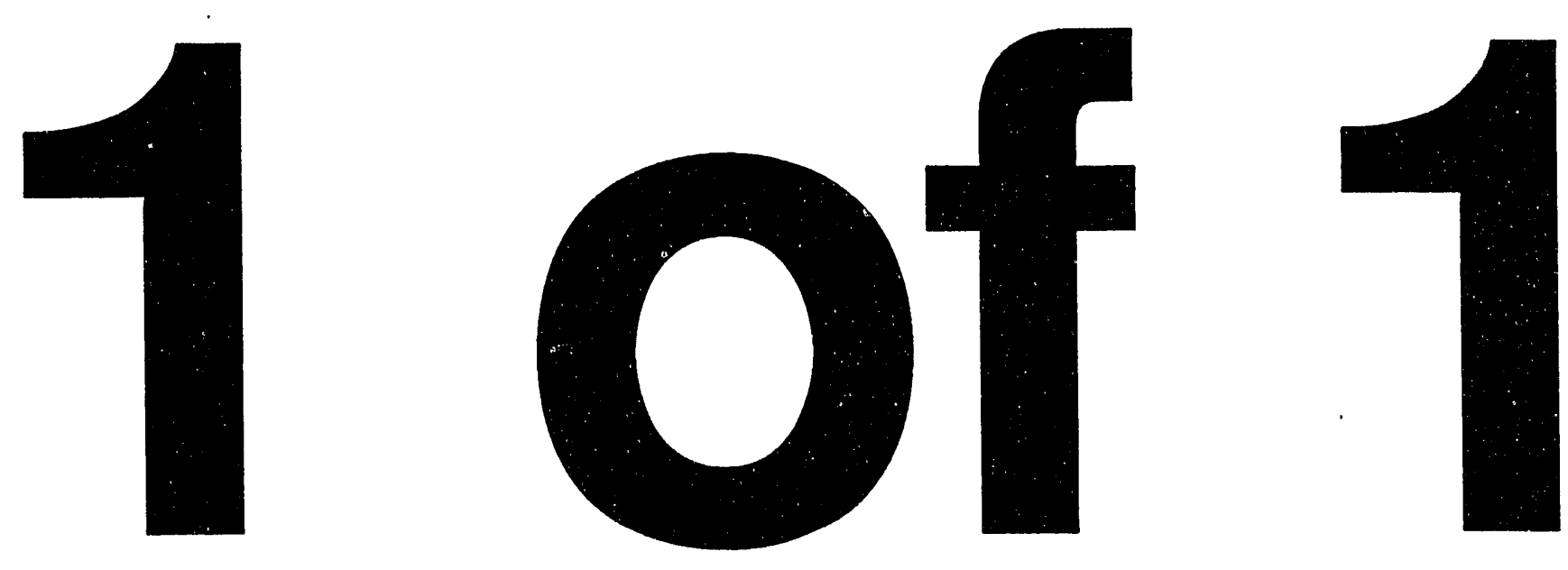


\title{
Upgrading of Western Shale Oil by Hydropyrolysis and Hydrotreating
}

\section{Topical Report}

\author{
James W. Bunger \\ Christopher P. Russell \\ Soon-Yong Jeong \\ Jiazhi Pu
}

July 1992

Work Performed Under Contract No.: DE-FC21-86MC1 1076

For

U.S. Department of Energy

Office of Fossil Energy

Morgantown Energy Technology Center

Morgantown, West Virginia

By

University of Utah

Department of Fuels Engineering

Salt Lake City, Utah 


\section{DISCLAIMER}

This report was prepared as an account of work sponsored by an agency of the United States Government. Neither the United States Government nor any agency thereof, nor any of their employees, makes any warranty, express or implied, or assumes any legal liability or responsibility for the accuracy, completeness, or usefulness of any information, apparatus, product, or process disclosed, or represents that its use would not infringe privately owned rights. Reference herein to any specific commercial product, process, or service by trade name, trademark, manufacturer, or otherwise does not necessarily constitute or imply its endorsement, recommendation, or favoring by the United States Government or any agency thereof. The views and opinions of authors expressed herein do not necessarily state or reflect those of the United States Government or any agency thereof.

This report has been reproduced directly from the best available copy.

Available to DOE and DOE contractors from the Office of Scientific and Technical Information, P.O. Box 62, Oak Ridge, TN 37831; prices available at (615) 576-8401.

Available to the public from the National Technical Information Service, U.S. Department of Commerce, 5285 Port Royal Rd., Springfield, VA 22161; phone orders accepted at (703) 487-4650. 
Upgrading of Western Shale Oil by Hydropyrolysis and Hydrotreating

\author{
Topical Report
}

James W. Bunger

Christopher P. Russell

Soon-Yong Jeong

Jiazhi Pu

Work Performed Under Contract No.: DE-FC21-86MC11076

\author{
For \\ U.S. Department of Energy \\ Office of Fossil Energy \\ Morgantown Energy Technology Center \\ P.O. Box 880 \\ Morgantown, West Virginia 26507-0880
}

University of Utah

Department of Fuels Engineering

Salt Lake City, Utah

July 1992 


\section{SUMMARY}

A proof-of-concept study for a new shale oil upgrading and refining process was undertaken. This project is aimed at reducing upgrading costs, thereby making shale oil development more feasible for commercialization. Raw shale oil was topped to remove the most volatile components. The topped shale oil was distilled into three narrow boiling cuts, representing of $175-275^{\circ} \mathrm{C}\left(347-527^{\circ} \mathrm{F}\right), 275-365^{\circ} \mathrm{C}\left(527-689^{\circ} \mathrm{F}\right)$, and $365-455^{\circ} \mathrm{C}$ $\left(527-851^{\circ} \mathrm{F}\right)$, and a residue portion $\left(>455^{\circ} \mathrm{C}\right)\left(>851^{\circ} \mathrm{F}\right)$. The distillate cuts were used to study molecular weight effects, and the residue was used to test the performance of hydropyrolysis. Hydropyrolysis converts the heavy residue into lower boiling point materials which can be more easily hydrotreated.

In the experiment to test molecular weight effects, it was found that geometric hindrance accounts for the inhibition effect. Diffusion limitation and inhibition by competitive adsorption are not strong effects. These results imply that there is no process substitute for the requirement of molecular weight reduction.

In the experiment to test the performance of hydropyrolysis, average molecular weight is reduced from 495 to 359 at moderate severities. In HDN of the hydropyrolized residue, however, high process severities are still required to remove nitrogen to the level of refinery-acceptable-feed $(<0.15 w t \%)$.

Based on experimental data, the product slate is $1.9 \mathrm{wt} \%$ gas, $13.1 \mathrm{wt} \%$ gasoline, $27.3 \mathrm{wt} \%$ kerosene, $55.6 \mathrm{wt} \%$ total gas oil, $1.3 \mathrm{wt} \%$ vacuum residue, and $0.8 \mathrm{wt} \%$ coke with $1376 \mathrm{scf} / \mathrm{bbl}$ total hydrogen consumption. The removal of sulfur is $96 \%$, and that of nitrogen is $84 \%$. The concentration of sulfur in the final product is $0.038 \mathrm{wt} \%$, and that of nitrogen in final product is $0.26 \%$. The conversion of heavy residue to atmospheric distillate is $47 \%$. However, the remaining residue is partially upgraded as a refinery feed. 
The process sequence shows promise for effective molecular weight reduction and hydroprocessing of shale oil for transportation fuels. Future work should be conducted to determine optimum process conditions. 


\section{TABLE OF CONTENTS}

Page

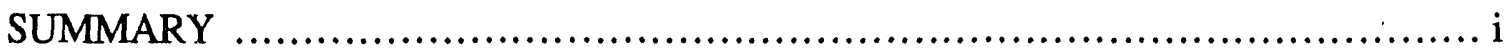

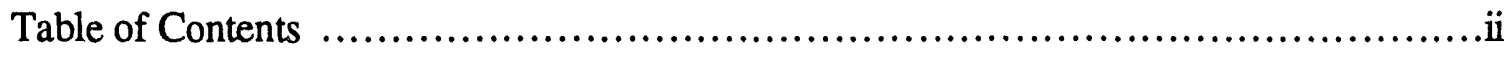

List of Tables...................................................................

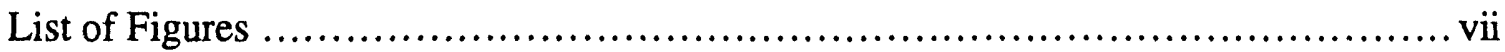

Chapter

1. Introduction ..................................................................

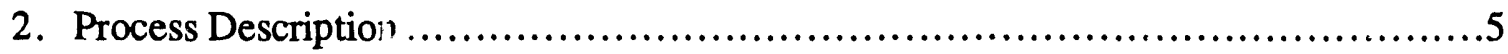

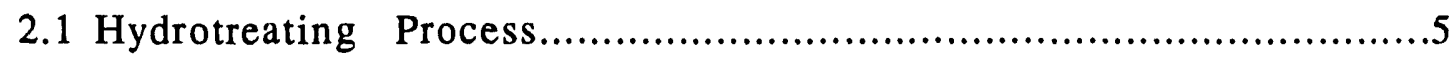

2.2 Hydropyrolysis Process ..............................................6

2.3 Proposed Shale Oil Upgrading Sequence Based on Theoretical Consideration .....7

3. Experimental ............................................................. 9

3.1 Apparatus ............................................................... 9

3.2 Starting Materials ....................................................... 11

3.3 Experimental Methodology ............................................. 12

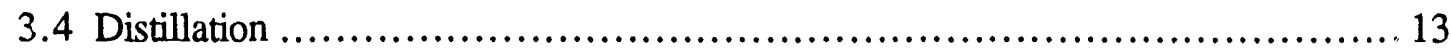

3.5 Catalyst Selection and Pretreatment.............................................. 15

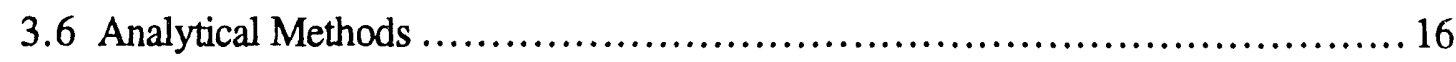

4. Results and Discussion .......................................................... 19

4.1 Catalytic Hydrotreating...................................................... 19

4.2 Hydropyrolysis ..................................................... 23

4.3 Catalytic Hydrotreating of HP Product.......................................... 25

5. New Upgrading Process Sequence of Shale Oil................................. 28 
5.1 Comparison with Conventional Upgrading Sequence

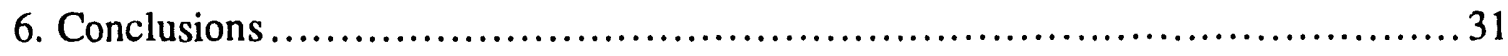

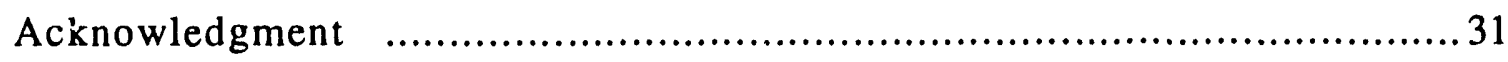

Disclaimer.......................................................................... 31

References .................................................................... 32

Glossary of Terms......................................................... 33

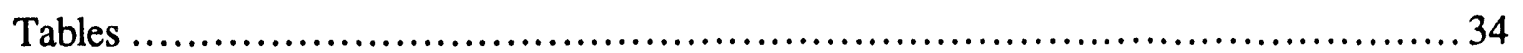

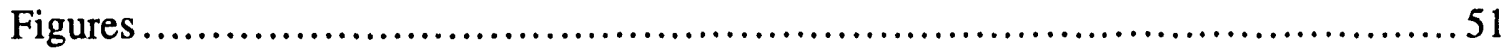


List of Tables

Table

Page

1. Elemental Analysis and Physical Properties of Raw Shale Oil ................... 34

2. Physical Properties of Model Compounds......................................... 35

3. Boiling Point Distribution of the WRI As-Received Shale Oil and

Topped Shale Oil.............................................................. 36

4. Boiling Point Distribution of Fractional Distillation Cuts and Residue from

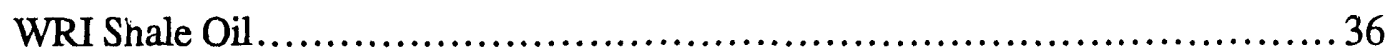

5. Physical and Thermodynamic Properties of

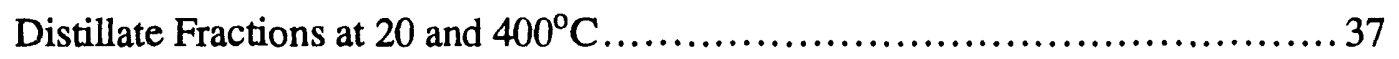

6. Properties of Catalyst................................................. 38

7. Typical Operating Conditions of Gas Chromatographs .......................... 39

8. Elemental Analysis of Distillates of Shale Oil and Distillates of

Shale Oil Hydortreated at $375^{\circ} \mathrm{C}, 1500 \mathrm{psig}$,

$1.43 \mathrm{cc} /\left(\mathrm{g}_{\mathrm{cat}} \mathrm{hr}^{\mathrm{hr}}\right) \mathrm{LHSV}$ and $2200 \mathrm{Scf} \mathrm{H}_{2} /$ bbl oil.......................... 40

9. Simulated Distillation Data of Feedstocks and Products After

Hydrotreating at $375^{\circ} \mathrm{C}, 1500 \mathrm{psig}, 1.43 \mathrm{cc} /\left(\mathrm{g}_{\mathrm{cat}}\right.$-hr) LHSV,

and $2200 \mathrm{Scf} \mathrm{H}_{2} / \mathrm{bbl}$ oil

10. Physical Properties of Feed and Product after Hydrotreating at $375^{\circ} \mathrm{C}$, $1500 \mathrm{psig}, 1.43 \mathrm{cc} /\left(\mathrm{g}_{\mathrm{cat}} \mathrm{hr}^{\mathrm{hr}}\right) \mathrm{LHSV}$ and $2200 \mathrm{Scf} \mathrm{H}_{2} / \mathrm{bbl} \mathrm{oil} \mathrm{...}$

11. Indole and Benzothiophene Contents of Feed and Products

after Hydrotreating at $370^{\circ} \mathrm{C}, 1500 \mathrm{psig}, 1.43 \mathrm{cc} /\left(\mathrm{g}_{\mathrm{cat}}-\mathrm{hr}\right)$, LHSV

and $2200 \mathrm{Scf} \mathrm{H}_{2} / \mathrm{bbl}$ oil.

12. Properties of Hydropyrolysis Feedstock and Liquid Product 
13. The Composition of Gas Product Stream after Hydropyrolysis

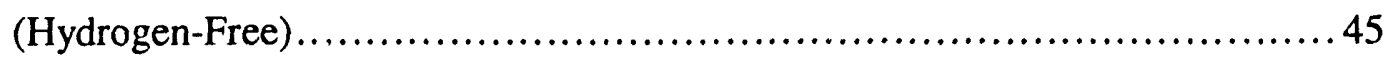

14. Summary of Hydroteating Studies of HP Product................................. 46

15. Characteristics of Hydrotreating Liquid Products................................... 47

16. Gas Composition of Hydrotreating Products...................................... 48

17. Simulated Distillation and Elemental Analysis of

Feedstock and Calculated Properties of a Final Product ........................ 49

18 Comparison with Conventional Upgrading Sequence..............................5 50 


\section{List of Figures}

Figure Page

1. Adsorption Equilibrium Constants of Paraffins................................ 51

2 Composition of Feed Streams and Absorbed Species on the Surface

of Catalyst a) Broad M.W. Range b) Narrow M.W. Range ................. 52

3. Proposed Shale Oil Upgrading Sequence..................................... 53

4. Schematic Diagram of Hydrotreating Unit................................ 54

5. Schematic Diagram of Trickle Bed Reactor................................. 55

6. Schematic Diagram of Gas Handling System of Hydropyrolysis

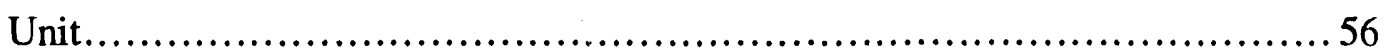

7. Schematic Diagram of Liquid Handling System of Hydropyrolysis

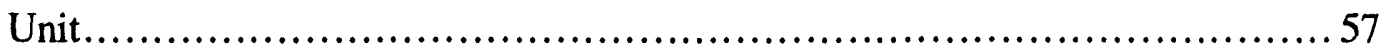

8. Experimental Works for Confirming Competitive Adsorption Effects ............. 58

9. Nitrogen Conversion Versus Total Reaction Time for Investigating the Catalyst

Deactivation.

Reaction Conditions : $375^{\circ} \mathrm{C}, 1500 \mathrm{psig}, 1.43 \mathrm{cc} /\left(\mathrm{g}_{\mathrm{cat}}-\mathrm{hr}\right) \mathrm{LHSV}$

and $2200 \mathrm{Scf} \mathrm{H}_{2} /$ bbl oil using Whole Shale Oil

10. Simulated Distillation of Three Distillates and Three Distillates Hydrotreated at

$375^{\circ} \mathrm{C}, 1500 \mathrm{psig}, 1.43 \mathrm{cc} /\left(\mathrm{g}_{\mathrm{cat}}{ }^{-\mathrm{hr}}\right) \mathrm{LHSV}$, and

$2200 \mathrm{Scf}_{2} /$ bbl oil

11. Simulated Distillation of Mixture and Mixture Hydrotreated

at $375^{\circ} \mathrm{C}, 1500 \mathrm{psig}, 1.43 \mathrm{cc} /\left(\mathrm{g}_{\mathrm{cat}}-\mathrm{hr}\right) \mathrm{LHSV}$

and $2200 \mathrm{Scf}_{2} / \mathrm{bbl}$ oil 
12. Simulated Distillation of Residue of Shale Oil and Hydropyrolyzed Product Reaction Conditions : $510^{\circ} \mathrm{C}, 1800 \mathrm{psig}, 1.71 \mathrm{sec}$ for Gas Residence Time, 1.08 Feed/Gas Ratio....................................................6 62

13. HDN Kinetics of HP Product about the Pseudo First Order Reaction ............6 63

14. Simulated Distillation of Feed and Product of Hydrotreating at Various Reaction Times ............................................. 64

15. New Upgrading Sequence for Shale Oil ................................65 


\section{Chapter 1 Introduction}

Upgrading of raw shale oil to refinery-acceptable crude oil adds significantly to the cost of shale oil production. The high cost of upgrading contributes to the marginal economics for oil shale commercialization. An improvement in the efficiency of shale oil upgrading and a reduction in costs would help advance the development of oil shale in the United States.

Currently practiced upgrading approaches encounter several difficulties which must be addressed in any advanced upgrading process. Shale oil also contains a high concentration of nitrogen which must be removed catalytically before the shale oil is acceptable as a feedstock to a conventional refinery. Shale oil also contains large quantities of conjugated olefins, such as indenes, indoles, and pyrroles, which are difficult to completely hydrogenate. Nitrogen compounds left in the shale oil cause long-term instability of the shale oil.

Raw shale oil also contains appreciable quantities of particles and metals such as vanadium, nickel, iron, and arsenic. The presence of iron and arsenic is particularly significant because catalysts used in conventional petroleum processing have not been designed for the presence of these metals.

Much of the difficulty with nitrogen removal relates to the catalytic hydroprocessing of the heavy end of the shale oil. Atmospheric residue typically constitutes $50 \%$ or more of the raw shale oil. To effect nitrogen removal from this material, high-process severities are required which result in high hydrogen consumption and reduced catalyst life due to coking reactions. High severities result in poor control over the product slate.

The literature contains numerous articles on shale oil upgrading and processing. ${ }^{1-3}$ Various schemes are proposed for dealing with the inherent difficulties of shale oils. Some schemes involve prior coking of the raw shale oil to reduce the molecular weight and to sequester undesirable inorganics in the cokc. While such schemes make the down-stream 
catalytic processing easier, coking results in a significant loss in yield; the advantages obtained are offset by the higher costs in the mining and retorting processes. Larger amounts of material must be handled to obtain a given output of product.

Upgrading and converting the entire raw shale oil distillation profile to high value marketable products has not yet been achieved. Historically, a significant portion of the final product is sold for fuel oil, because of the cost and difficulty in converting the residual end of shale oil to transportation fuels. At the present time conventional refineries will not accept a raw shale oil, and catalytic hydroprocessing must be effected prior to refining.

Shale oil was upgrading at the several-thousand bbl/day level by UNOCAL. ${ }^{4}$ The upgrading sequence consisted of passing raw shale oil over a catalyst/guard bed to remove metals and particles. The shale oil then passed over hydrotreating catalysts for nitrogen and sulfur removal and for hydrogenation of olefins. Mild hydrocracking of paraffins could be included for pour point control.

Crude Paraho shale oil was upgraded into military transportation fuels by the Standard Oil Company. ${ }^{5}$ The upgrading sequence was comprised of passing raw shale oil over an alumina/guard bed to remove metals and particulates. Then, shale oil was passed over Shell 324 hydrotreating catalyst to remove nitrogen and sulfur. In this process, the guard bed was plugged by the build-up of iron sulfide fines between the catalyst pellets and also frum the formation of a black pitch on the top of the bed. This process suggested that the key to successful commercial scale refining of shale oil will lie on the shale oil pretreatment steps.

For sequences which do not involve hydrocracking, the hydrogen requirements for denitrogenation typically exceed $2,000 \mathrm{scf} / \mathrm{bbl} .^{6}$ For these approaches, less than $15 \%$ of the finished product boils in the naphtha range $\left(80\right.$ to $200^{\circ} \mathrm{C}$ ). This means that additional cracking and hydroprocessing is required at the refinery for production of gasoline and middle distillates (diesel or aviation turbine fuels). Thus, currently practiced technology 
results in high hydrogen consumption, low yields of products in the desirable boiling range, and less-than-desirable catalyst life.

Stoichiometry calculations show that complete removal of nitrogen, sulfur, and oxygen to form $\mathrm{NH}_{3}, \mathrm{H}_{2} \mathrm{~S}$, and $\mathrm{H}_{2} \mathrm{O}$, respectively, and saturation of olefinic bonds requires approximately $800 \mathrm{scf} / \mathrm{bbl}$. Additionally, ring hydrogenation is required for certain structures to allow removal of ring heteroatoms. Theoretical thermodynamic considerations suggest that high selectivity for HDN, HDS, HYD can not be achieved when operating at high process severities. Theoretical considerations have also shown that high selectivity is extremely difficult when processing higher molecular weight aromatics. This results because condensed aromatics of two rings or larger are more susceptible to hydrogenation than are single-ring aromatics. In addition, process severity hign enough to result in HDN also results in hydrogenation of multiple ring aromatic hydrocarbons.

The high rate of catalyst deactivation and the inability to project a cost effective refining and market option for the residual portion make the assessment of upgrading costs very difficult. There are three basic characteristics of raw shale oil which contribute to the high costs of upgrading and refining which must be addressed in any advanced scheme for processing these materials. The first of these is the metals and particulates content; the second of these is the extraordinarily high nitrogen content, much of which is pyrrolic and pyridinic in nature; the third characteristic is the relatively large fraction of atmospheric residue in comparison to light and middle distillate. Ordinarily, the atmospheric residue or vacuum gas oil is charged to catalytic crackers, but the high nitrogen content of these high boiling materials makes the catalytic cracking option unacceptably expensive. An advanced upgrading and refining approach must account for these three critical factors.

The objective of this project is to develop an advanced shale oil upgrading process which can solve these critical problems. This advanced upgrading process would involve the following: 
1. A method for reducing the molecular weight of the residual fraction to light and middle atmospheric distillate.

2. A method for avoiding poisoning or fouling by metals and inorganics.

3. A means for optimizing the catalytic processing of higher molecular weight species.

4. A process sequence which minimizes hydrogen consumption and maximizes liquid yields while meeting criteria for refinery acceptability. Such a process promises higher process efficiency and is expected to result in significantly reduced shale oil upgrading costs. 


\section{Chapter 2 Process Description}

\subsection{Hudrotreating Process}

An important discovery has been made in the catalytic processing research. In a study to determine the effects of adsorption thermodynamics on catalytic reactions ${ }^{7}$, it has been learned that the value of the adsorption constant $\mathrm{K}_{\mathrm{ads}}$ is a strong function of molecular weight. Fig. 1 shows that the adsorption constant of paraffinic compounds increase with increase of molecular weight. It is expected that higher molecular weight compounds are more strongly absorbed on the surface of the catalyst. Aromatic compounds and heteroatom compounds may show the same trend as paraffinic compounds. Also, structural features, including the presence of most heteroatoms, play a secondary role in determining the magnitude of $\mathrm{K}_{\mathrm{ads}}$. In the first order reaction rate equation :

$$
\begin{aligned}
\mathrm{r} & =\mathrm{k} \mathrm{K} \mathrm{K}_{\mathrm{a}} \mathrm{A} /\left(1+\sum \mathrm{K}_{\mathrm{i}} \mathrm{X}_{\mathrm{i}}\right) \\
\text { where, } \mathrm{A} & =\text { Heteroatom concentration } \\
\mathrm{k} & =\text { Kinetic constant } \\
\mathrm{K}_{\mathrm{i}} & =\text { Adsorption constant of species } \mathrm{i} \\
\mathrm{X}_{\mathrm{i}} & =\text { Concentration of species } \mathrm{i} \\
\mathrm{K}_{\mathrm{a}} & =\text { Adsorption constant of heteroatom }
\end{aligned}
$$

The adsorption constant for absorbed species appears as an inhibition term in the denominator. If a feedstock exhibiting a broad range of molecular weight is passed over a catalytic surface, in theory, the highest molecular weight species will successfully compete for adsorption on the surface, displacing lower molecular weight species and thereby inhibiting the opportunity for these lower molecular weight species to react. 
This phenomenon is illustrated graphically in Figure 2. Figure 2-a depicts a theoretical feedstock of a broad molecular weight range with an average of $300 \mathrm{amu}$. If this material were to be passed over a catalyst surface, under steady state conditions, the molecular weight distribution of absorbed species calculated from Horng's model ${ }^{7}$ is shown by the "dashed" line. At a temperature of $350^{\circ} \mathrm{C}$, all but the highest molecular weight species would be effectively excluded from the surface. An increase in temperature to $410^{\circ} \mathrm{C}$ improves the situation. But it is still clear that a large fraction of the feedstock would be inhibited from adsorption. Figure 2-b illustrates the case in which a narrow molecular weight range material is passed over the catalyst. In this case, a much larger fraction of the feedstock participates in the adsorption process and thereby is afforded an opportunity to react.

The implication of these calculations to shale oil processing is obvious. If shale oil upgrading is to be achieved with high selectivity and acceptable conversions at moderate process severities, the feedstock to the catalytic process must be of a narrow molecular weight range. A narrow molecular weight range is most conveniently achieved through distillation into narrow boiling cuts (here it is recognized that the effect of structural differences in molecular will limit how narrow the range can be). The practical limit of how narrow the fraction should be and how many parallel hydrotreaters are required is, in fact, an economic question.

\subsection{Hydropyrolysis Process}

Hydropyrolysis is a thermal hydrocracking process which has been under development at the University of Utah for more than a decade. ${ }^{8-11}$ The Utah hydropyrolysis process is a short-residence time $(1-3 \mathrm{sec})$ and moderate temperature (500 $-600^{\circ} \mathrm{C}$ ) process for the cracking of residual materials to distillate products. Feedstock is introduced to the reaction zone containing $1200-2000 \mathrm{psig}_{2}$ by use of a spray nozzle. Hydrogen participates in the reaction by methathesis reactions with hydrocarbon free 
radicals. Hydrogen atoms produced in the methathesis reactions accelerate cracking, dealkylation, cracking of naphthenic compounds, and partial hydrogenation of PNAs. During hydropyrolysis, reduction of molecular weight occurs with virtually no production of coke. Coke-forming reactions are almost completely inhibited by the action of hydrogen and the dilute phase of the reaction regime. Reduction of the molecular weight is acl. :eved with very modest net hydrogen consumption. A reduction of average molecular weight by $50 \%$ is typically accomplished by a net hydrogen consumption of only $200-300 \mathrm{scf} / \mathrm{bbl}$. Theoretical calculation shows that this is very close to the minimum hydrogen requirements for one cracking event per molecule, assuming that there is no net dehydrogenation of naphthenes to aromatics.

An important feature of hydropyrolysis is its relative insensitivity to inorganics and metals. These species do not adversely affect the process and tend to end up in the unreacted residual portion of the products. The process may be operated at low severities to minimize gas production and unreacted material can be recycled to improve the conversion. A small drag stream of the heaviest components containing the majority of the particulates and metals is removed from the reaction system. Thus, hydropyrolysis is a process which promises to convert heavy shale oil to distillate products in high yields and with low consumption of hydrogen.

\subsection{Proposed Shale Oil Upgrading Sequence Based on Theoretical Consideration}

A new approach to the shale oil processing is illustrated in the flow diagram shown in Figure 3. The initial step in the process is a fractionation of raw shale oil into an atmospheric distillate and an atmospheric residue. The residue, which contains the vast majority of the inorganics, is fed to the hydropyrolysis reactor designed to operate at moderate severity. Unreacted material is recycled to improve the conversion. A hydrogenrich stream is recycled for conservation of hydrogen. By operating at moderate severities, high conversions to distillate liquids with low hydrogen consumption is achieved. The 
distillate material, boiling in the range of $80-350^{\circ} \mathrm{C}$ is recombined with the overhead in the original distillation step. This material is fractionated to produce " $n$ " fractions for hydrotreating. Hydrotreating is conducted in a parallel reactor under conditions specifically optimized for the distillate cut. The hydrotreater may or may not contain guard beds, depending upon the metals content of the fuel. 


\section{Chapter 3 Experimental}

\subsection{Apparatus}

\section{3.l.l Catalytic Hydrotreating Unit}

The purpose of hydrotreating is to remove heteroatoms such as N, S, and $\mathrm{O}$ by passing the oil over the surface of a catalyst under high hydrogen pressure. The removal of $\mathrm{N}, \mathrm{S}$, and $\mathrm{O}$ to form $\mathrm{NH}_{3}, \mathrm{H}_{2} \mathrm{~S}$, and $\mathrm{H}_{2} \mathrm{O}$ requires consumption of hydrogen. The hydrotreating unit was constructed and used to remove heteroatoms in the distillates of shale oil. Figure 4 shows a schematic diagram of the hydrotreating unit.

Feed System : The feedstock, contained in a scaled feed vessel, was pumped to system pressure by a Milton Roy high pressure reciprocating pump (capacity $=130 \mathrm{ml} / \mathrm{hr}$, 3000 psig rating). The liquid feed rate and accumulated amount was monitored and recorded by a scaled feed vessel. Feedstock was heated for pumping, sent through a preheating zone, and charged to the top of the reactor.

Reactor System : In these studies, a trickle bed reactor was used, the reactor consisted of a 316 stainless steel tube ( $2.54 \mathrm{~cm}$ O.D. x $1.9 \mathrm{~cm}$ I.D. $\times 42 \mathrm{~cm}$ long) packed with catalyst. The reactor was designed to minimize the axial and dispersion effects by adjusting the ratio of reactor length and catalyst diameter. The reactor tube was heated by a furnace and the reaction temperature was controlled by a proportionating temperature controller (Love Controller Model No 53), and monitored by a thermocouple located at the exterior of the reactor. A thermocouple well located axially along the center of tube allowed the interior reactor temperature to be monitored. The reactor tube and catalyst bed are shown in Figure 5. The top $7 \mathrm{~cm}$ of the reactor was packed with small $1 / 8$ " glass spheres to act as a preheating zone. A mixture of about $50 \mathrm{~g}$ of catalyst and $38 \mathrm{~g}$ of $10-20$ mesh glass beads was loaded into the reactor. It was found that this glass bead dilution gave more consistent results, eliminated bypassing, decreased axial dispersion and allowed for more isothermal operation in the presence of exothermic reactions. The bottom $3 \mathrm{~cm}$ of the 
reactor was packed with $1 / 8^{\prime \prime}$ glass spheres to act as support for the catalyst particles. A fine stainless steel screen was placed on the top of the reactor to serve as a distributor plate.

Gas system : Hydrogen was passed through a high pressure regulator and hydrogen flow rate was monitored by a mass flow meter. Hydrogen was heated in the preheating zone and entered the top of the reactor, flowing cocurrently with feed. Liquid and gas trickled through the catalyst bed. In the separator, the products were separated into liquid product and gases. Gases consist of the reaction products $\left(\mathrm{NH}_{3}, \mathrm{H}_{2} \mathrm{~S}\right.$, and light hydrocarbon gases) and mostly unreacted hydrogen. Gases were passed through micrometering valves to adjust gas flow rate. A wet test meter was used to monitor gas flow rate and accumulated amount. A multipoint chart recorder was used to monitor temperatures throughout the system.

When the desired reactor temperature was reached, the feed flow rate was set with the metering pump and the hydrogen flow was established at $2100-2300 \mathrm{scf}_{2} / \mathrm{bbl}$. A period of up to 1 hour was allowed for the reactor to reach equilibrium temperature and system pressure. When all operating conditions were stable, liquid product was collected in the product vessel for about $2-6$ hours.

\section{1 .2 Hydropyrolysis Unit}

Hydropyrolysis is a short residence time, non-catalytic thermal hydrocracking process for reducing the molecular weight of residual components without the formation of coke. Hydropyrolysis can crack atmospheric and vacuum residue to atmospheric distillate, rendering the nitrogen and sulfur compounds amenable to conventional catalytic hydrotreating.

The hydropyrolysis unit was revamped and specially prepared for hydropyrolysis of the residue of shale oil. Figures 6 and 7 show a schematic diagram of the hydropyrolysis unit which has two sections, the gas handling system and the liquid handing system. 
The shale oil residue feedstock is pumped at system pressure and heated to 350 $400^{\circ} \mathrm{C}$ by the liquid preheater. Fresh hydrogen is mixed with a hydrogen-rich recycle gas stream, compressed to system pressure, and heated to about $600^{\circ} \mathrm{C}$ by the gas preheater. Then, preheated feedstock is introduced to the reactor by the use of a spray nozzle to provide good contact between preheated gas and preheated liquid. In the first separator, the products are separated into light product including gases and heavy product. Heavy product is either recycled to the inlet of the liquid preheater or collected in the pot. The light product is cooled, and then separated into gases and light product. Gases consist of the reaction products (mainly light hydrocarbon) and unreacted hydrogen. Some of the gases are purged by a back pressure regulator to prevent the system pressure from increasing by the buildup of light hydrocarbon gases. Most gases are recycled. Cool hydrogen is used initially to prevent nozzle plugging by coking reactions. The cooling hydrogen keeps the temperature of the nozzle below coking temperature. After feed and hydrogen pass through the nozzle, the cooling hydrogen is shut off. The nozzle does not plug at stable flowing conditions.

\section{Starting Materials}

\subsubsection{Shale Oil Characteristics}

The shale oil characteristics are shown in Table 1. Samples of shale oil were obtained from Western Research Institute (WRI) and the New Paraho Shale Oil Corporation. The WRI sample was generated in the 10 ton retort circa 1985/86. The samples have been subjected to elemental analysis and physical properties measurements. The data in Table 1 show that Paraho shale oil has a slightly higher density and viscosity and lower volatility than the WRI shale oil. Paraho shale oil also has a slightly higher content of nitrogen, lower sulfur content, and lower $\mathrm{H} / \mathrm{C}$ atom ratio. In selecting a sample for use, consideration was given to the principal experimental tasks of the program, namely, the hydropyrolysis and hydrotreating. The WRI sample is a better test sample for 
the hydrotreating portion because of its higher yield of distiliate. The Paraho shale oil is a better test sample for the hydropyrolysis because of its higher residue content. From these two samples, the WRI sample was selected because large amounts of distillate are required for the hydrotreating study. Both of these samples are typical for shale oil with high nitrogen contents and $50 \%$ or more atmospheric residue. Both samples are suitable for study for the proof-of-concept of the proposed shale oil refining process.

\section{2 .2 Model Compound}

High purity model compounds used were: indole as a representative of nitrogen compounds, and benzothiophene as a representative of sulfur compounds. Hexadecane was used as solvent. They served to evaluate competitive adsorption effects due to molecular weight of the shale oil fractions. The properties of these model compounds are listed in Table 2.

\subsection{Experimental Methodology}

In order to confirm inhibition effects due to competitive adsorption as stated in chapter 2, two types of experimental procedure are used,

(1) Shale oil was distillated into three fractions and a residue. The three fractions represent the $175-275,275-365$, and $365-455^{\circ} \mathrm{C}$ boiling point ranges. The three distillates serve as feeds of narrow molecular weight distribution and an equal weight mixture of the three fractions serves as a feed with a broad range of molecular weight. These four samples are hydrotreated through the trickle bed reactor under identical conditions. Average performance of the three distillate cuts is compared with performance of the equal weight mixture.

(2) Indole, as representative of $\mathrm{N}$-containing compounds, is mixed with each of the three distillate cuts and the equal weight mixture of three distillates to investigate 
competitive adsorption effects on HDN. Also benzothiophene, as representative of Scontaining compounds, is mixed with the three distillate cuts and the equal weight mixture of thu three distillates to examine competitive adsorption effects by molecular weight. The four prepared samples are hydrotreated under identical condition. Average percent removal of indole and benzothiophene in the three distillates is compared with percent removal of indole and benzothiophene in the equal weight mixture. Figure 8 shows pictorially experimental methods.

In order to test the performance of hydropyrolysis, the residue of shale oil was processed through the hydropyrolysis unit. Process conditions were selected from optimum conditions which are obtained by a process model ${ }^{12}$ and based on economic considerations. The hydropyrolized residue of shale oil is processed through the catalytic hydrotreator to confirm that the HP product is much more amenable to HDN than the original material because of reduction of molecular weight .

\subsection{Distillation}

The distillation is carried out in two steps. The first is to top shale oil, removing the most volatile components; the second is to distill the topped shale oil, yielding narrow boiling point fractions and a residue. The distillate portions are used as feedstocks to the hydrotreating unit, and the residue is used as feedstock to the hydropyrolysis unit.

\subsubsection{Topping of Shale Oil}

The shale oil was subjected to thin-film distillation for purposes of topping the shale oil and removing the most volatile components. In this-film distillation, which is applied to high-boiling substances (mainly of a temperature-sensitive nature), the material is distilled at a pressure $<10^{-3}$ torr in an apparatus constructed in such a way that the distance travelled by the molecules between the evaporating and condensing surfaces is shorter than their mean free path. The purpose of this arrangement is that the majority of the evaporated 
molecules reach the condensing surface without being deflected by collision with foreign gas molecules. The equilibrium between evaporated molecules and the liquid is continually disturbed by condensation so that, in accordance with physical laws, equilibrium has to be established.

The WRI sample to be distilled underwent a preliminary degassing (still temperature $=150^{\circ} \mathrm{C}$, still pressure $=640$ torr) to minimize the amount of uncondensible gas present. Uncondensible and volatile components are easily hydrotreatable, but their presence in the samples results in increasing difficulties with material balances and their removal will improve the final results. The degassed sample was then distilled in a KDT4 laboratory short-path distillation apparatus manufactured by Leybold-Heraeus GMBH \& CoKG, Cologne.

The fractional distillation compositions of the as-received shale oil and the topped shale oil are shown in Table 3. Approximately $12.4 \%$ of the shale oil was distilled and condensed. The light end condensate exhibited an API gravity of 40.8. The topped shale oil, representing nearly $16 \mathrm{~kg}$ of material and $87.6 \%$ of the original material, exhibited an API gravity of 22.0. The simulated distillation data for these two samples are shown in Table 3.

\section{4 .2 Distillation of Topped WRI Sample}

The degassed and topped WRI Shale Oil was distilled by the Series 3650 Semi-Cal fractional laboratory distillation unit under 20 torr to obtain three fractions and a residue. The three fractions are representative of the $175-275,275-365$, and $365-455^{\circ} \mathrm{C}$ boiling ranges. The efficiency of the separation was determined by simulated distillation analysis of the three fractions. Boiling point distributions of the fractional distillation cuts and the residue are shown in Table 4 . These three fractions were used in the hydrotreating process. The residue was subjected to hydropyrolysis. 
A process simulation method developed by Simulation Sciences Inc. was used to calculate the important physical and thermodynamic properties of these three fractions based on a pseudo-component concept. These results, taken at ambient temperature and at $400^{\circ} \mathrm{C}$, are shown Table 5. These data were used in theoretical calculations.

\subsection{Catalyst Selection and Pretreatment}

\section{Catalyst Selection}

Hydrotreating catalysts are most commonly sulfided forms of Mo or W, promoted with $\mathrm{Co}$ or Ni. The support is usually gamma-alumina or stabilized alumina without silica. The low acid support is designed to reduce cracking as opposed to hydrocracking catalysts, where strong acid functions are present. Promoted Co catalyst results in lower hydrogen consumption than promoted Ni catalyst. ${ }^{12}$

For these studies, $\mathrm{Co}-\mathrm{Mo} / \mathrm{Al}_{2} \mathrm{O}_{3}$ catalyst was selected to minimize hydrogen consumption. Two types of Co-Mo/ $/ \mathrm{Al}_{2} \mathrm{O}_{3}$ catalyst were obtained from Shell Development Company. The properties of these two $1 / 16$ inch catalysts are listed in Table 6 . The data in the table show that the chemical compositions are nearly identical with the 344 catalyst possessing a lower specific surface area compared to the 444 catalyst. The catalyst of lower specific surface area typically exhibits higher average pore diameters. For purposes of proof-of-concept studies, it was desirable to limit the pore diffusion effects as much as possible so that the conversions and rates measured are more representative of the intrinsic catalytic reaction rates. Therefore, the 344 catalyst was selected for these studies.

\section{Catalyst Pretreatment}

Catalyst was dried to remove moisture before presulfiding because moisture on the catalyst inhibits presulfiding. Catalyst was dried in a muffle furnace at $371^{\circ} \mathrm{C}$ for 2 hours.

The method by which the catalyst is loaded depends upon the size of the reactor and the nature of the feed being treated. In this study, catalyst was mixed with $10-20$ mesh glass bead (catalyst : glass bead $=4: 3$, weight basis). 
After loading catalyst in the reactor, the catalyst was presulfided by passing a gas stream containing $10 \% \mathrm{v} / \mathrm{v} \mathrm{H}_{2} \mathrm{~S}$ in $\mathrm{H}_{2}$ through the reactor at $400^{\circ} \mathrm{C}$ for 5 hours at a rate of $10 \mathrm{~L} / \mathrm{hr}$. Then, catalyst was lined out to maintain a constant activity of the catalyst. Process conditions and materials used for the line-out studies were :

$\mathrm{T}=375^{\circ} \mathrm{C}$

System Pressure $=1500$ psig

LHSV $=1.43 \mathrm{cc} /$ (g cat. hr)

$\mathrm{H}_{2} /$ oil ratio : $2200( \pm 100) \mathrm{scf} / \mathrm{bbl}$

Material $=$ Whole shale oil

Catalyst activity during this long run was checked after every $20-40$ hours by repeating a standard set of run conditions. Figure 9 shows nitrogen conversion versus total reaction time. From this result, the catalyst was lined out after 60 hours, and the activity of the catalyst was maintained during operating period.

\subsection{Analytical Methods}

Liquid product streams of hydropyrolized and hydrotreated shale oil were analyzed by simulated distillation, density measurement, viscosity measurement, and elemental analysis for $\mathrm{C}, \mathrm{H}, \mathrm{N}, \mathrm{S}$. The quantitative analysis of model compounds in liquid products was achieved by capillary gas chromatography.

The gas product streams of hydrotreated and hydropyrolized shale oil were analyzed by a Carle Analytic gas chromatograph including FID and TCD detectors. Typical operating conditions of the gas chromatograph are summarized in Table 7.

\section{Simulated Distillation}

The boiling point distributions of feedstocks and products were determined by a simulated distillation using a Hewlett-Packard model 5730A gas chromatograph according to the ASTM D3710 standard method. A Hewlett Parkard 3550 data acquisition system 
programmed with appropriate software was used to electronically record, calculate, and report data.

\section{Elemental Analysis}

Elemental analysis of hydropyrolized products was performed by a commercial laboratory using conventional microanalysis for $\mathrm{C}, \mathrm{H}, \mathrm{N}$, and $\mathrm{S}$. Hydrotreated products generally contain small amount of heteroatoms. Thus, nitrogen was analyzed by the Kjeldahl method, and sulfur was analyzed by the trace analysis method.

\section{Density}

Density was determined on a Parr/Mettler DM40 digital densitometer at $60^{\circ} \mathrm{F}$ to obtain the specific gravity.

Viscosity

Viscosity measurements were conducted with a Brookfield Viscometer Model LVT at $25^{\circ} \mathrm{C}$ or higher temperature.

Quantitative Analysis of Model Compounds in Liquid Product.

The quantitative analysis of model compounds in liquid products was achieved by capillary gas chromatography. Because these liquid products are a complex mixture, the peaks of indole and benzothiophene are overlapped by peaks from shale oil fractionated at $175-275^{\circ} \mathrm{C}$ in the chromatogram. The area of peaks for indole or benzothiophene are determined by the following way.

At first, an internal standard (toluene)which does not overlap the distillate cuts is selected. The internal standard is added to shale oil. After obtaining the chromatogram, the true area of the peak of indole or benzothiophene is obtained by the peak separation technique. The weight percent of indole or benzothiophene is determined by the following equation.

$$
\begin{aligned}
& \mathrm{W}_{\mathrm{s}}=\mathrm{W}_{\mathrm{int}}\left(\mathrm{A}^{*} / \mathrm{A}_{\mathrm{int}}\right) \mathrm{F} \\
& \mathrm{A}^{*}=\mathrm{A}_{\mathrm{int}}\left(\mathrm{W}_{1} / \mathrm{W}_{2}\right)
\end{aligned}
$$


Where, $\mathrm{W}_{\mathrm{s}}=\mathrm{Wt} \%$ of indole or benzothiophene in sample

$\mathrm{W}_{\mathrm{int}}=\mathrm{Wt} \%$ of internal standard in sample

$\mathrm{A}_{\text {int }}=$ Area of internal standard peak

$\mathrm{A}^{*} \quad=$ The true area of indole or benzothiophene peak

$\mathrm{W}_{1}=$ The weight of recorder paper of internal standard peak area

$\mathrm{W}_{2}=$ The weight of recorder paper of true peak area

$\mathrm{F} \quad=$ Response factor

The peak areas were integrated by geometric (?) means because this technique could account for judgmental factors better than electronic integration of unresolved peaks. In order to determine the response factor, $1 \mathrm{wt} \%$ of indole (or benzothiophene) and $1 \mathrm{wt} \%$ of internal standard in solvent are mixed. After obtaining the gas chromatogram, the response factor is calculated by the following equation.

$\mathrm{F}=\mathrm{A}_{\mathrm{s}} / \mathrm{A}_{\mathrm{int}}$

where, $A_{s}=$ The peak area of indole or benzothiophene in the mixture

$A_{\text {int }}=$ The peak area of internal standard in the mixture 


\section{Chapter 4 Results and Discussion}

\subsection{Catalytic Hydrotreating}

\section{Method I}

To verify the competitive adsorptions effects described in chapter 2 , the following experiments were conducted. Three distillate fractions, representing narrow molecular weight distributions, were processed through the fixed-bed catalytic hydrotreater. An equal weight mixture of the three fractions as a representative of a broad molecular weight distribution was processed under identical conditions.

Experimental conditions were intentionally selected to limit the amount of conversion in order to maximize differences resulting from different feed boiling points. The experimental conditions were the following:

Reaction Temperature : $375^{\circ} \mathrm{C}$

LHSV : $1.43 \mathrm{cc} /\left(\mathrm{g}_{\mathrm{cat}}{ }^{-\mathrm{hr}}\right)$

System Pressure : 1500 psig

$\mathrm{H}_{2}$ flow rate : $2200 \mathrm{scf} \mathrm{H}_{2}$ / bbl

Results of the elemental analysis of the feedstocks and products are given in Table 8. They show that nitrogen increases with increasing boiling point and nitrogen removal decreases as boiling point of the fraction increases. A similar trend is seen for the sulfur removal. Because the three fractions were combined in equal weights to form the mixture, a check of the elemental analysis can be made by comparing the average of the three fractions with the results obtained on the actual mixture. These results show good agreement.

A significant observation in the results is that the average conversion of nitrogen for the three fractions is not significantly different from that of mixture, contrary to the theoretical expectations proposed in this work. The average conversion of sulfur for the 
three fractions is slightly higher than that of mixture. But this difference is within the error of analysis.

The most obvious explanation is that while heavy heteroatom species exhibit lower conversion rates they do not inhibit light heteroatom species from reacting with the surface of catalyst. The reaction rate is not influenced by the competitive adsorption effect according to molecular weight. If this is the case, adsorption equilibrium constants may not vary much with molecular weight for heteroatom compounds.

Another significant observation in the results is that the average hydrogen/carbon atom ratio for the three products is not significantly different from that of the product of mixture. These results seem consistent with the observed conversion of nitrogen and sulfur, if most hydrogen is consumed by hydrogenation and hydrogenolysis in the hydrotreating reaction.

Simulated distillation of various fractions are given in Table 9 and pictorially shown in Figures 10 and 11. Results show that the original distillation was quite efficient and that there is a small amount of cracking that occurs in the hydrotreating process. The HDS and HDN processes would, of course, tend to reduce molecular weight, even if there were no cracking of $\mathrm{C}-\mathrm{C}$ bonds.

Physical property data of density and viscosity are shown in Table 10. This table shows increasing density and viscosity with boiling point and reduction of density and viscosity with hydrotreating, as expected.

A comparison of the average of the density with those of the mixture, before and after hydrotreating, reveal no substantial difference between the behavior of the individual fractions when processed separately and that of the mixture. These results would tend to confirm those that were observed in the conversion of nitrogen and sulfur.

\section{Methou 2}

A second reaction is carried out using three distillate fractions, spiked with a model compounds, to reconfirm inhibition effects on HDS and HDN by competitive adsorption 
due to molecular weight. These experiments are designed to investigate whether selfinhibition effects by nitrogen compounds in oil exist or not.

For these studies, benzothiophene and indole were selected as representatives of sulfur-containing compounds and nitrogen containing compounds. Five wt $\%$ of benzothiophene and $5 \mathrm{wt} \%$ of indole were added to three distillate fractions and were hydroprocessed through the fixed bed catalytic hydrotreating unit at identical conditions. The same amount of indole was also added to hexadecane, to investigate self-inhibition effects by nitrogen compounds in fractions. Conditions for these experiments were :

Reactor Temperature : $370^{\circ} \mathrm{C}$

System Pressure : 1500 psig

LHSV : $1.43 \mathrm{cc} /\left(\mathrm{gcat}_{\mathrm{cat}} \mathrm{hr}^{\mathrm{h}}\right)$

$\mathrm{H}_{2} /$ Oil ratio : $2200( \pm 100) \mathrm{scf} / \mathrm{bbl}$

The quantitative analysis of model compounds in liquid products was achieved by capillary gas chromatography. However, since the peaks of indole and benzothiophene were overlapped by the peaks of shale oil fractionated at $175-275^{\circ} \mathrm{C}$ in the chromatogram, the actual areas of the peaks of indole or benzothiophene were obtained by the peak separation technique. This peak separation technique was described in section 3.6. Various intermediate compounds are produced during the hydrodenitrogenation of indole and benzothiophene. However, it is impossible to analyze quantitatively for these intermediate compounds which are not completely decomposed, because nitrogen containing compounds in the fractions react simultaneously and produce many compounds by hydrogenation and hydrogenolysis reactions. Bhinde ${ }^{13}$ found through model compounds studies that inhibition effects by nitrogen compounds confirm both hydrogenation and hydrogenolysis. Therefore, the competitive inhibition effect can be explained by the hydrogenation of indole and benzothiophene. 
Results are shown in Table 11. A significant observation is that the average conversion of indole in the three fractions is not considerably different from that for the mixture, reconfirming the previous result that there is not a significant competitive adsorption effect due to molecular weight. The conversions of indole in Table 11 are the average of duplicated runs within $\pm 2.0 \mathrm{wt} \%$ error. The percent removal of indole in hexadecane is higher than that of indole in shale oil fractions. The obvious explanation would seem to be that the conversion of indole is influenced by inhibitory nitrogen compounds. However, inhibition due to a higher concentration of inhibitory nitrogen compounds is an unlikely explanation for reduction in hydrogenation rate of indole, because the percent removal of indole in each fraction is not significantly different as the concentration of nitrogen increases from 0.99 to $2.15 \mathrm{wt} \%$ through the series of feedstocks.

Another observation is that percent removal of benzothiophene in each distillate cut is slightly down with heavier fraction, and the average conversion of benzothiophene of the three fractions is a little higher than that of the mixture. It is difficult to explain the competitive ansorption according to increase of molecular weight of sulfur compounds, because the rate of HDS is significantly influenced by inhibitory nitrogen compounds ${ }^{12}$. Therefore, a small difference between the average conversion of benzothiophene of the three fractions and that of mixture may be due to inhibition by nitrogen compounds.

We may conclude that an inhibition effect on HDN by competitive adsorption due to molecular weight is not significant. However, inhibition effects by inhibitory nitrogen compounds still exists. From these results, it is suggested that adsorption equilibrium constants may be less dependent on molecular weight for heteroatom compounds, and may be a strong function of structure of nitrogen compound. This suggestion is supported by model compound studies. ${ }^{13}$ Since a basic nitrogen compound is strongly absorbed on the surface of catalyst, adsorption equilibrium constants of basic nitrogen compounds are relatively larger than those of non-basic nitrogen compounds. For example, the HDN rate 
of indole-type nitrogen compound is strongly inhibited by quinoline-type nitrogen compounds, but the HDN rate of a quinoline compound is less inhibited by an indole type nitrogen compound.

\subsection{Hydropyrolysis}

The residue of shale oil was processed through the hydropyrolysis unit. Process conditions were selected from optimized conditions which were obtained from a process model ${ }^{14}$ based on tar sand bitumen which possesses typically over $50 \%$ vacuum residue. The optimum conditions are involved in mild conditions because they focus on the economic consideration. The process conditions are follows:

Reactor temperature : $510^{\circ} \mathrm{C}$

System pressure : $1800 \mathrm{psig}$

Feed flow rate $: 33.5 \mathrm{~g} / \mathrm{min}$

Gas flow rate : $31 \mathrm{~g} / \mathrm{min}$

Gas residence time : $1.71 \mathrm{sec}$

Feed/Gas weight ratio : 1.08

The complex mixture is separated into specified boiling ranges to provide individual products of commercial importance such as residue (R), total gas oil (TGO), naphtha and middle distillate (NMD), and gas (G). The knowledge that the molecular weight is a strong function of its boiling point and material of high molecular weight cracks to lower molecular weight species suggests the following relatively simple scheme for representing the overall kinetics:

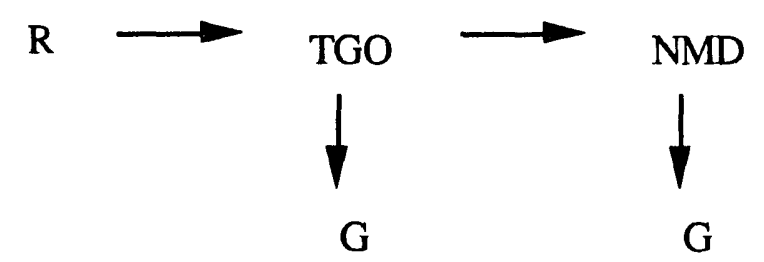

where $\mathrm{R}$ is the weight fraction of residue exhibiting a normal boiling point above $538^{\circ} \mathrm{C}$, TGO is the weight fraction of total gas oil with a normal boiling point of 275 - 
$538^{\circ} \mathrm{C}, \mathrm{NMD}$ is the weight of fraction of naphtha and middle distillate boiling at 1 atm up to $275^{\circ} \mathrm{C}\left(\mathrm{C}_{5}-275^{\circ} \mathrm{C}\right)$, and $\mathrm{G}$ represents the weight fraction of gases $\left(\mathrm{C}_{4} \mathrm{~s}\right.$ and below, dry gas).

Results of the simulated distillation of liquid product and feed are given in Table 12, and pictorially shown in Figure 12. The hydropyrolysis data of the residue of shale oil (including total gas oil 55.3\%, and 44.7 residue) show good conversion to $9.6 \%$ naphtha and middle distillate, $64.0 \%$ total gas oil, and $26.5 \%$ residue at short residence time (1.71 sec). Liquid yield was $89.2 \%$ of the weight of feedstock and $2.1 \%$ coke was produced. Relatively little gas product was produced $(8.7 \%)$, and relatively small conversion to naphtha and middle distillate was seen. The process conditions were chosen on the basis of economic considerations which favor high yield of naphtha and middle distillate and less coking. Better conversion might be achieved with an increase in residence time.

Average molecular weight of feed and product are estimated by the Process Simulation Software developed by Simulation Science Inc. These results show that average molecular weight is significantly reduced. Thus, the HP product will be much more amenable to catalytic hydrotreating than the original material.

Elemental analysis data are shown Table $12 . \mathrm{H} / \mathrm{C}$ atomic ratio increase slightly, and heteroatom removal is slight because of non-catalytic thermal reactions. However, the HP product of residue of shale oil (ROS) still has a high nitrogen content. Nitrogen in the HP product should be removed before using it as a refinery feedstock.

An attempt was made to quantify hydrogen consumption because of its importance to process economics. The hydrogen consumption can be estimated by material balance considerations as outlined in the literature. ${ }^{15}$ This calculation method is quite sensitive to yield, and it is assumed that all heteroatoms not found in the product liquid are hydrogenated, and coke formation is presumed to be zero. Since the small amount of coke formation occurs in hydropyrolysis units, this assumption is reasonable, but depending on 
error of yield, hydrogen consumption could still be in error. From this calculation, hydrogen consumption is $864 \mathrm{scfH}_{2} / \mathrm{bbl}$ oil, indicating mild hydrogen consumption.

Density data are shown in Table 12. This table shows, as expected, minor reduction of density with hydropyrolysis. Because hydropyrolysis does not reject carbon and aromatics to coke, HP products will rarely show a major improvement in API even though substantial upgrading has occurred in terms of molecular weight reduction and increased volatility. Also, viscosity data are shown in Table 12. These data show that viscosity has been significantly reduced by hydropyrolysis.

Table 13 shows analysis of the gas product stream from hydropyrolysis of residue of shale oil. The composition of product gas mainly consists of unreacted hydrogen, and light hydrocarbons such as methane, ethane, and propane. The production of olefins is small.

\subsection{Catalytic Hydrotreating of HP Product}

The residue of shale oil has a high concentration of nitrogen associated with large molecular weight compounds. Since the molecular weight decreased through hydropyrolysis, the HP product should be significantly amenable to catalytic hydrotreating. HP product was processed through the trickle bed catalytic hydrotreater to investigate the possibility of use as petroleum feedstock. The HP product still has a high nitrogen content. This high concentration of nitrogen should be removed by higher severity conditions before the HP product is acceptable as a feedstock to a conventional refinery. HP product mainly consists of gas oil (boiling point $275-538^{\circ} \mathrm{C}$ ). In this boiling point range, nitrogen compounds such as alkyl-substituted quinoline and benzoquinoline, and dibenzopyrroles have been found. ${ }^{16}$ These compounds are hard to completely hydrogenate. Thus, high process severities may be required to remove to the refinary-acceptable-level of nitrogen content $(<0.15 \mathrm{wt} \% \mathrm{~N})$. Operating conditions were selected to prevent catalyst from being deactivated by coking reactions. Reaction temperature and hydrogen pressure were fixed at $390^{\circ} \mathrm{C}$ and $1800 \mathrm{psig}$ (relatively mild temperature and pressure), and contact time was 
variable. These conditions are shown in Table 14. As reaction time increases from 0.70 to $2.70\left(\mathrm{~g}_{\mathrm{cat}}-\mathrm{hr}\right) / \mathrm{cc}$, the production of gas increases from $2.4 \mathrm{wt} \%$ to $6.3 \mathrm{wt} \%$ of feed, assuming no coke is produced.

Table 15 shows the results of elemental analysis of liquid products. As reaction time increases from $0.70 \mathrm{hr}$ to $2.70\left(\mathrm{~g}_{\mathrm{cat}}-\mathrm{hr}\right) / \mathrm{cc}$, sulfur content decrease from $0.105 \mathrm{wt} \%$ to $0.059 \mathrm{wt} \%$, and at the same reaction times, nitrogen content decreases from $1.18 \mathrm{wt} \%$ to $0.41 \mathrm{wt} \%$, confirming that the percent removal of sulfur is larger than that of nitrogen. Generally the nitrogen content of refinery-acceptable-feed is limited to $0.15 \mathrm{wt} \%$. In order to meet this criterion, more severe process conditions are required.

The nitrogen conversion predicted from a recently developed model for HDN conversion model based on molecular weight ${ }^{17}$ was compared with the actual hydrotreating data of the hydopyrolyzed residue of shale oil. The predicted nitrogen conversion was 58 $\mathrm{wt} \%$ at $390^{\circ} \mathrm{C}, 1800 \mathrm{psig}$ and $0.7\left(\mathrm{~g}_{\mathrm{cat}} \mathrm{hr}^{\mathrm{hr}} \mathrm{cc}\right)$. The experimental result was $34 \mathrm{wt} \%$ nitrogen conversion at the same reaction condition. These results showed additional effects, which are not yet identified such as compound type effects, exist.

Figure 13 shows the HDN kinetics with commercial Co-Mo hydrotreating catalyst. HDN is very close to a pseudo first order reaction with a reaction rate constant of 0.55 $\mathrm{cc} /\left(\mathrm{g}_{\mathrm{cat}}-\mathrm{hr}\right)$. In order to meet the criterion of nitrogen content, reaction time should be 4.34 $\left(\mathrm{g}_{\mathrm{cat}} \mathrm{hr}\right) / \mathrm{cc}$ at $390^{\circ} \mathrm{C}$ and $1800 \mathrm{psig}$. Longer reaction times result in high hydrogen consumption, and reduces catalyst life due to coking reactions.

The simulated distillation data at various reaction times, are presented in Table 15 and shown in Figure 14. Results shows that severe hydrocracking by cleavage of carbon bonds occurs with an increase of reaction time. Also, hydrogen consumption increases from $672 \mathrm{scf} / \mathrm{bbl}$ to $1235 \mathrm{scf} / \mathrm{bbl}$ as reaction time increases from $0.70 \mathrm{hr}$ to 2.70 ( $\left.\mathrm{g}_{\mathrm{cat}}-\mathrm{hr}\right) /$ cc. Density and viscosity data are shown in Table 15. Specific gravity and viscosity decrease with increase of reaction time because of $\mathrm{c}-\mathrm{c}$ bond cracking reactions. 
Composition of the gas stream at various reaction times are shown in Table 16. Product gas mainly consists of unreacted hydrogen, methane, ethane, and propane. The composition of the gas product is not significantly changed with increase of reaction time. 


\section{Chapter 5 New Upgrading Sequence of Shale Oil}

In the experiments to confirm the competitive adsorption effect, it has been found that the average heteroatom removal for the three distillates is not significantly different from that for an equal weight mixture of the three distillates. Therefore, distillate cuts of shale oil need not be made solely to reduce kinetic inhibition. A normal optimization may still be indicated to provide for high selectivity and utilization of hydrogen. In subsequent work ${ }^{16}$, it has been determined that molecular weight effects are due to geometric hindrance.

A new upgrading sequence for processing shale oil is shown in Figure 15. These results are based on experimental data. The initial step is a fractionation of raw shale oil into distillate $\left(<455^{\circ} \mathrm{C},<851^{\circ} \mathrm{F}\right)$ and residue $\left(>455^{\circ} \mathrm{C},>851^{\circ} \mathrm{F}\right)$. Distillate is hydrotreated without the fractionation of distillate. Two different operating conditions, representing low severity and high severity, were selected to calculate the total hydrogen consumption, total heteroatom removal and total conversion of heavy residue to distillate product. Operating conditions of low severity are $375^{\circ} \mathrm{C}, 1800 \mathrm{psig}$ and $1.43 \mathrm{cc} /\left(\mathrm{g}_{\mathrm{cat}}{ }^{-\mathrm{hr}}\right.$ ) (LHSV), and those of high severities are $400^{\circ} \mathrm{C}, 1800 \mathrm{psig}, 0.70 \mathrm{cc} /\left(\mathrm{g}_{\mathrm{cat}}{ }^{\mathrm{hr}}\right)$ (LHSV).

Residue is fed to the hydropyrolysis unit designed to operate at modest severities. HP residue, which contains the majority of particles and metals, is drained, or is recycled to improve conversion. Then the HP product is hydrotreated. The two different operating conditions (low severity: $390^{\circ} \mathrm{C}, 1800 \mathrm{psig}$ and $0.71 \mathrm{cc} /\left(\mathrm{g}_{\mathrm{cat}}{ }^{\text {-hr) }}\right.$ (LHSV), high severities: $390^{\circ} \mathrm{C}, 1800 \mathrm{psig}$ and $0.37 \mathrm{cc} /\left(\mathrm{g}_{\mathrm{cat}}\right.$-hr) (LHSV) were also selected to investigate whether the final product meets the level of nitrogen content for refinery acceptability or not. The final results of elemental analysis were calculated by the combination of two different hydrotreated products. At low severities, total sulfur conversion is $81.6 \%$, and total nitrogen conversion is $66 \%$ with $1130 \mathrm{scf} / \mathrm{bbl}(2.03 \mathrm{wt} \%)$ of total hydrogen consumption. The nitrogen content of residue which was passed through the hydropyrolysis unit and 
hydrotreator was $0.67 w t \%$. A significant observation of this result is that the HDN of hydropyrolized residue is still difficult. At high severities, total sulfur conversion is very high $(96 \%)$, and total nitrogen conversion is $84 \%$ with $1376 \mathrm{scf} / \mathrm{bbl}(2.42 \mathrm{wt} \%)$ of total hydrogen consumption. Nitrogen level, however, is still higher than the criteria of refinery acceptability because the nitrogen content of residue hydrotreated at high severities is still high $(0.41 w t \%)$. Therefore, higher process severities for hydrotreating and hydropyrolysis are required to produce as a feedstock for a refinery. A higher severity in the hydropyrolysis unit may results in easier-to-hydrotreat products.

Table 17 shows the results of simulated distillations of the final product and feedstock. The final result was calculated by the combination of two product streams. At low severities, atmospheric distillate $\left(<350^{\circ} \mathrm{C}\right)$ is increased from 39.3 to $51.0 \mathrm{wt} \%$ with $6.38 \mathrm{wt} \%$ total gas production. At high severities, atmosphere distillate $\left(<350^{\circ} \mathrm{C}\right)$ is increased from 39.3 to $67.8 \mathrm{wt} \%$ with $7.22 \mathrm{wt} \%$ total gas production. An important observation is that this upgrading sequence of shale oil converts heavy residue to atmospheric distillate with high yield.

\section{Comparison with Conventional Upgrading Sequence}

Summary results of the proposed process scheme are given in Table 18 and compared with results of conventional hydroprocessing of whole raw paraho shale oil. Conventional processing involves catalytic HDN of whole raw shale oil using guard beds

for particulates and metals removal. ${ }^{6}$ To make the data comparable at constant conversion some interpolation of Sullivan's data was required.

Data show that for the easily removed nitrogen, there is not much advantage to the proposed scheme, but at higher severities, the advantage becomes measurable. The proposed method results in a significantly higher yield of distillate due to the hydropyrolysis step. The proposed scheme yields higher quantities of distillate for the same hydrogen consumption at similar nitrogen ' onversion levels. For this reason, the 
proposed scheme deserves further study. If in future studies it can be demonstrated that the proposed approach exhibits attractive economics, then improved hydrogen utilization will have been achieved. This was one of the original objectives of the curient research. 


\section{Chapter 6 Conclusions}

1. It has been found that inhibition effects by competitive adsorption due to molecular weight are not significant. However, HDN rates still decline with increasing molecular weight, showing the importance of molecular weight reduction to improved catalytic hydroprocessing.

2. In the experiment to study the performance of hydropyrolysis, molecular weight is reduced from 495 to 359 at moderate conditions, and atmospheric distillate converted from heavy residue increases from $39.3 \mathrm{wt} \%$ in feed to $67.8 \mathrm{wt} \%$ in the final product. The residue processed in the hydropyrolysis unit becomes amenable for catalytic hydrotreating. However, high process severities are required to meet the criteria for refinery acceptability.

3. In the new upgrading process for shale oil, the end slate is calculated to be 1.9 wt\% gas, $13.1 \mathrm{wt} \%$ gasoline, $27.3 \mathrm{wt} \%$ kerosene, $55.6 \mathrm{wt} \%$ total gas oil, $1.3 \mathrm{wt} \%$ vacuum residue, and $0.8 \mathrm{wt} \%$ coke with $1376 \mathrm{scf} / \mathrm{bbl}$ total hydrogen consumption. The total conversion of sulfur is $96 \%$, leaving a sulfur content of $0.038 \mathrm{wt} \%$. The total conversion of nitrogen is $84 \%$, leaving a nitrogen content of $0.26 \mathrm{wt} \%$.

\section{ACKNOWLEDGMENT}

Funding of this work was provided under cooperative agreement DE-FC86MC11076 from the U.S. Department of Energy.

\section{DISCLAIMER}

Mention of specified brand names or models of equipment is for information only and does not imply endorsement of any particular brand. 


\section{References}

1. Sladek, T.A., Poulton, P.L., Davis, W.E., and Robinson, P.A., "A Technology Assessment of Oil Shale Development," 13th Oil Shale Symposium Proceeding, Colorado School of Mines, 1980.

2. Ranney, M.W., "Shale Oil Refining and Purification Processes," Oil Shale and Tar Sands Technology, Recent Developments, p. 233, Noyes Data Corporation, 1979.

3. Hendrickson, T.A., Synthetic Fuels Data Handbook, Cameron Eng., Inc., 1978.

4. Personal Communication, UNOCAL, Feb. 1989.

5. Robinson, E.T. and Evin C.G., "Commercial Scale Hydrotreating of Shale Oil," Shale Oil Upgrading and Refining, p. 49, Butterworth Publishers, 1983.

6. Sullivan, R.F., and Stangeland, B.E., Chapter 3, Refining of Synthetic Crudes, Gorbatty, M.L., and Harney, B.M., eds., ACS-Adv. Chem. Ser., 179, 25, 1979.

7. Horng, J. H., " Thermodynamics of Chemisorption as Relative to Catalytic Hydroprocessing of Coal-Derived Liquids," Thesis, The University of Utah, Fuels Engineering, 1987.

8. Bunger, J. W., and Cogswell, D. E., "Characteristics of Tar Sand Bitumen Asphaltenes as Studied by Conversion of Bitumen by Hydropyrolysis," Chapter 13 of Chemistry of Asphaltenes, J. W. Bunger, N. C. Li (eds.). Advances in Chemistry Series - 195, American Chemical Society, 1981.

9. Bunger, J. W., Cogswell, D. E., and Oblad, A. G., "Hydropyrolysis - Potential for Primary Upgrading" in Oil Shale, Tar Sand and Related Materials, Harry Stauffer, ed., ACS Symposium Series - 163, Chapter 25, pp. 369-380, 1981.

10. Bunger, J. W.and Oblad, A. G., " Upgrading of Bitumen by Hydropyrolysis - A Process for Low Coke and High Syncrude Yields," Proc. Third Internat. Conf. of Heavy Crude and Tar Sands, UNITAR/UNDP Information Center New York City, Los Angeles, CA, pp. 1717-1726, July 22-31, 1985.

11. Bunger, J. W., Tsai, C. H., Ryu, H., and Devineni, P., "Developments in Upgrading of Bitumen by Hydropyrolysis," Proceeding, 4th International Conference on Heavy Crude and Tar Sands, UNITAR/UNDP. Edmonton, Canada, 5, 169-176, 1988.

12. Satterfield, C. N., Mass Transfer in Heterogenous Catalysis, M.I.T. Press, 1970.

13. Bhinde, M. V., "Quinoline Hydrodenitrogenation Kinetics and Reaction Inhibition," Ph.D. Dissertation, University of Delaware, Newark, 1979.

14. Ryu, H., "Kinetic Modeling Applied to Hydrocarbon Process Design and Engineering," Ph.D Dissertation, University of Utah, Department of Fuels Engineering, 1989.

15. Bunger, J. W., "Processing Utah Tar Sand Bitumen," Ph.D. Thesis, University of Utah, Salt Lake City, UT, 1979. 
16. Bett, G , Harvey T.G., Matheson, T.W., and Pratt, K.C., " Determination of Polar Compounds in Rundle Shale Oil," Fuel, Vol 62, pp 1445-1453, 1983.

17. Jeong, S.,"Dependence of Reaction Kinetics on Molecular Weight in Hydroprocessing of Shale Oil and Tar Sand Bitumen," Ph.D Dissertation, University of Utah, Department of Fuels Engineering, 1992.

\section{Glossary of Terms}

HDN Hydrodenitrogenation

HDS Hydrodesulfurization

HP Hydropyrolysis

HYD Hydrogenation

LHSV Linear Hourly Space Velocity ( $\mathrm{cc} / \mathrm{g}_{\mathrm{cat}} \mathrm{t}^{\mathrm{hr}}$ )

PNA Polynuclear aromatic

WRI Western Research Institute 
Table 1. Elemental Analysis and Physical Properties of Raw Shale Oil

\begin{tabular}{|c|c|c|}
\hline Analysis & Paraho & WRI \\
\hline \multicolumn{3}{|l|}{ Element } \\
\hline $\mathrm{C}$ & 82.02 & 83.73 \\
\hline $\mathbf{H}$ & 11.07 & 11.53 \\
\hline $\mathbf{N}$ & 1.87 & 1.63 \\
\hline$S$ & 0.70 & 0.98 \\
\hline$O($ diff $)$ & 4.34 & 2.13 \\
\hline $\mathrm{H} / \mathrm{C}$ Atomic Ratio & 1.621 & 1.652 \\
\hline Arsenic (mg/kg) & - & $<0.4$ \\
\hline Iron $(\mathrm{mg} / \mathrm{kg})$ & -- & 216 \\
\hline \multicolumn{3}{|l|}{ Physical Properties } \\
\hline Sp. Gr. $15.6^{\circ} / 15.6^{\circ} \mathrm{C}$ & 0.9330 & 0.9155 \\
\hline API & 20.16 & 23.06 \\
\hline Viscosity (cp @25ㄷ) & 540 & 45 \\
\hline \multicolumn{3}{|c|}{ Simulated Distillation Data (wt \%) } \\
\hline$<275^{\circ} \mathrm{C}$ & 15.3 & 18.7 \\
\hline $275-365^{\circ} \mathrm{C}$ & 23.0 & 31.2 \\
\hline $365-455^{\circ} \mathrm{C}$ & 25.0 & 30.1 \\
\hline $455-538^{\circ} \mathrm{C}$ & 20.1 & 14.8 \\
\hline$>538^{\circ} \mathrm{C}$ & 16.6 & 5.2 \\
\hline Total & 100 & 100 \\
\hline
\end{tabular}




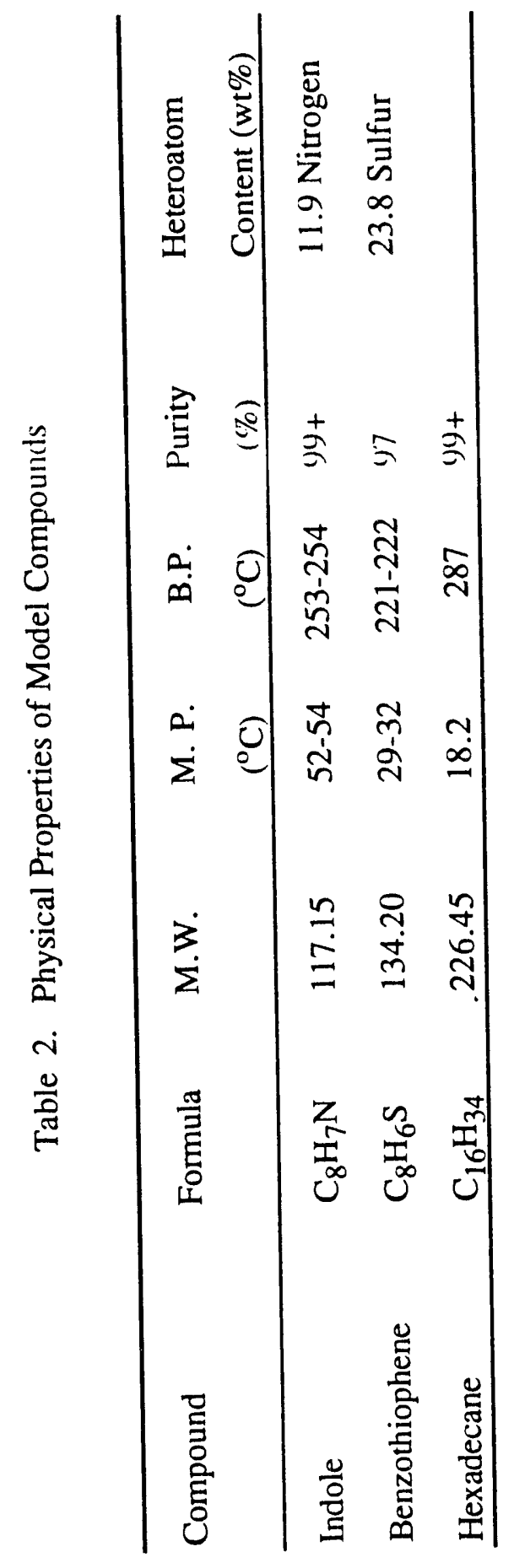


Table 3. Boiling Point Distribution of the WRI As-Received Shale Oil and Topped Shale Oil

\begin{tabular}{lcc}
\hline Boiling Point $\left({ }^{\circ} \mathrm{C}\right)$ & As Received Shale Oil & Topped Shale Oil (wt\%) \\
\hline Gasoline $\left(<200^{\circ} \mathrm{C}\right)$ & 2.6 & 0.2 \\
Kerosene $\left(200-275^{\circ} \mathrm{C}\right)$ & 16.1 & 11.5 \\
Gas Oil $\left(275-325^{\circ} \mathrm{C}\right)$ & 15.8 & 17.0 \\
Hvy GO $\left(325-400^{\circ} \mathrm{C}\right)$ & 27.8 & 30.9 \\
VGO $\left(400-538^{\circ} \mathrm{C}\right)$ & 32.5 & 33.0 \\
Vac. Residue $\left(>538^{\circ} \mathrm{C}\right)$ & $\underline{5.2}$ & $\underline{7.4}$ \\
Total & 100 & 100 \\
\hline
\end{tabular}

Table 4. Boiling Point Distribution of Fractional Distillation Cuts and Residue from WRI Shale Oil

\begin{tabular}{lcccc}
\hline Boiling Point $\left({ }^{\circ} \mathrm{C}\right)$ & 1 & 2 & 3 & Residue \\
\hline$<175^{\circ} \mathrm{C}$ & $0.6 \mathrm{wt} \%$ & - & - & - \\
$175-275^{\circ} \mathrm{C}$ & 98.3 & 0.4 & - & - \\
$275-365^{\circ} \mathrm{C}$ & 1.1 & 97.4 & 3.3 & \\
$365-455^{\circ} \mathrm{C}$ & - & 2.2 & $95 .+$ & 20.6 \\
$>455^{\circ} \mathrm{C}$ & - & - & 1.3 & 79.4 \\
Total & 100 & 100 & 100 & 100 \\
Fractionation Efficiency $(\%)$ & 98.3 & 97.4 & 95.4 & - \\
\hline
\end{tabular}




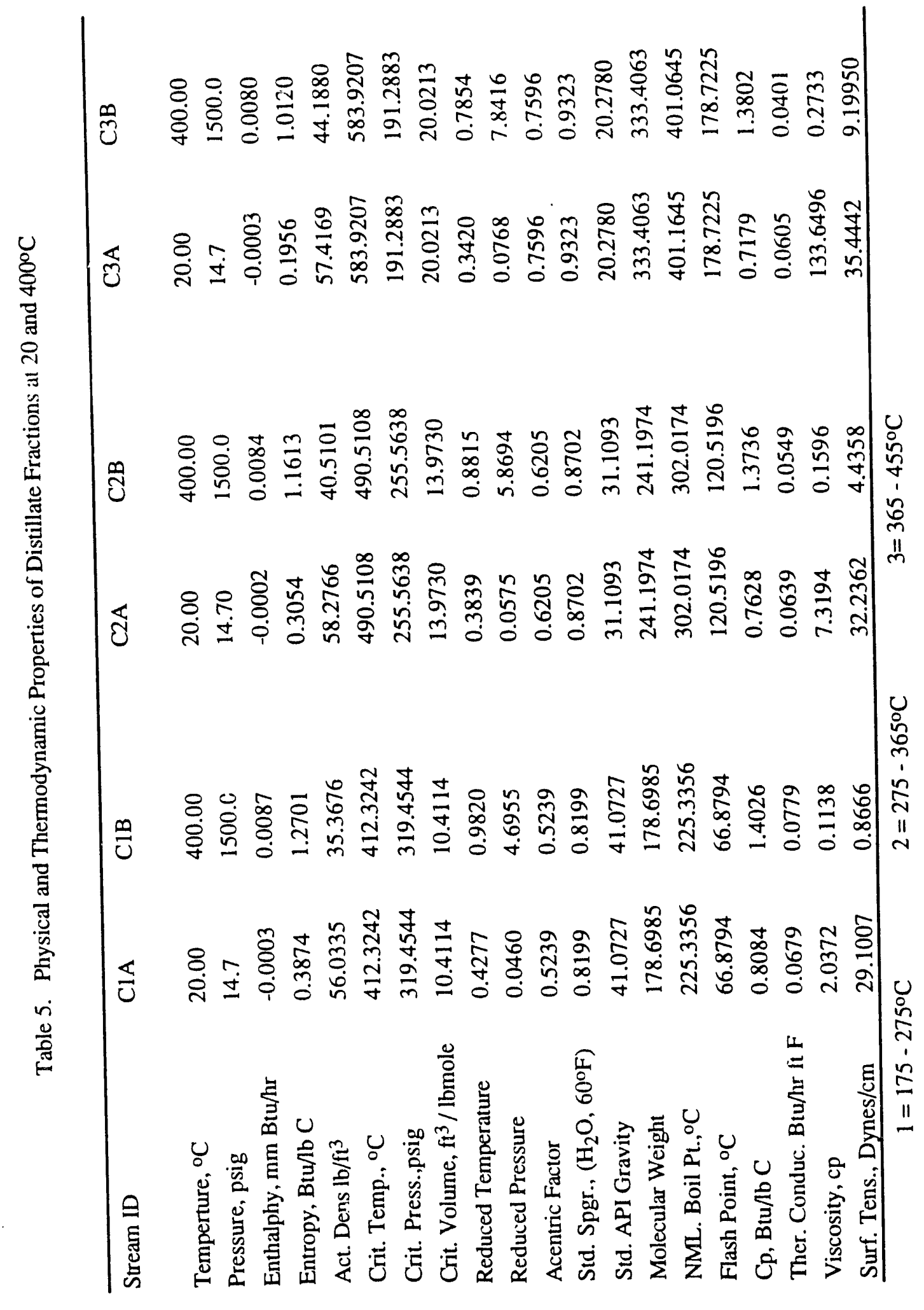


Table 6. Properties of Catalyst

\begin{tabular}{|c|c|c|}
\hline Catalyst & $344 \mathrm{~T} / \mathrm{L} 1 / 16$ & $444 \mathrm{~T} / \mathrm{L} 1 / 16$ \\
\hline Nominal Size, in (mm) & $1 / 16(1.5)$ & $1 / 16(1.5)$ \\
\hline \multicolumn{3}{|l|}{ Chemical Composition, wt \% } \\
\hline Cobalt & 2.52 & 3.22 \\
\hline Molybdenum & 9.85 & 9.59 \\
\hline \multicolumn{3}{|l|}{ Physical Properties } \\
\hline Surface Area, $\mathrm{m}^{2} / \mathrm{g}$ & 190 & 230 \\
\hline Pore Volume, cc/g & 0.56 & 0.57 \\
\hline Average Pore Radius, A & 58.9 & 49.6 \\
\hline Side Plate Crush Strength, lbs/ft $\mathrm{t}^{3}$ & 22.5 & 19.4 \\
\hline Attrition Index & 98.8 & 98.8 \\
\hline Compacted Bulk Density, lbs/ft ${ }^{3}$ & $45.0(0.72 \mathrm{~g} / \mathrm{cc})$ & 45.4 \\
\hline Loss on ignition at $900^{\circ} \mathrm{C}$, wt. $\%$ & 1.24 & 0.99 \\
\hline
\end{tabular}


Table 7. Typical Operating Conditions of Gas Chromatographs

\begin{tabular}{llll}
\hline Usage & $\begin{array}{l}\text { Simulated } \\
\text { Distillation }\end{array}$ & Gas Analysis & $\begin{array}{l}\text { Model Compound } \\
\text { in Liquid Product }\end{array}$ \\
\hline Model & HP5730 & Carle Analytical & HP5890 \\
Detector & FID & FID, TCD & FID \\
Column Length & $18^{\prime \prime}$ & $49^{\prime} 9^{\prime \prime}$ & $25 \mathrm{~m}$ \\
Column O. D. & $1 / 4^{\prime \prime}$ & $1 / 8^{\prime \prime}$ & $\mathrm{a}$ \\
Packing Material & $\mathrm{b}$ & $\mathrm{c}$ & $\mathrm{d}$ \\
Sample Size & $0.2 \mu \mathrm{l}$ & $\mathrm{TCD}: 500 \mu \mathrm{l}$ & $0.1 \mu \mathrm{l}$ \\
& & $\mathrm{FID}: 250 \mu \mathrm{l}$ & $(\mathrm{Split}$ Ratio $=22: 1)$ \\
Carrier Gas & $\mathrm{He}$ & $\mathrm{He}, \mathrm{N}_{2}$ & $\mathrm{He}, \mathrm{N}_{2}$ \\
Flow Rate & $50 \mathrm{cc} / \mathrm{min}$ & $60 \mathrm{cc} / \mathrm{min}$ & $30 \mathrm{cc} / \mathrm{min}$ \\
\hline
\end{tabular}

$\mathrm{a}: 0.032 \mathrm{~mm} \mathrm{ID} * 0.52 \mu \mathrm{m}$ film thickness megabore capillary column

b : 3\% Dexil 400 on $90 / 100$ mesh Anakrom Q

c : Column 1: 3\% Carbowax 1540 on Porasil C

Column 2A: 27.5\% BIS(EE)A on Chromosorb Paw

Column 2B: 3\% Carbowax 1540 on Porasil C

Column 2C: 0.4\% Carbowax 1540 on Carbopak B

Column 3,4: 28\% DC 200/500 on Chromosorb Paw,

$80 \%$ Porapak N+20\% Porapak Q

Column 5, 6: Molecular sieve 13X, Molecular sieve 5A

$\mathrm{d}$ : Crosslinked 5\% phenyl methyl silicone gum phase (HP-5) 
Table 8. Elemental Analysis of Distillates of Shale Oil and Distillates of Shale Oil Hydrotreated at $375^{\circ} \mathrm{C}, 1500 \mathrm{psig}, 1.43 \mathrm{cc} /\left(\mathrm{g}_{\mathrm{cat}}-\mathrm{hr}\right) \mathrm{LHSV}$ and $2200 \mathrm{Scf}$ $\mathrm{H}_{2} /$ bbl oil

\begin{tabular}{|c|c|c|c|}
\hline Item & Feed & Product & Conversion $(\%)$ \\
\hline \multicolumn{4}{|l|}{ Sulfur content } \\
\hline Fraction $1\left(175-275^{\circ} \mathrm{C}\right)$ & 0.89 & 0.12 & $86.5( \pm 2.3)$ \\
\hline Fraction $2\left(275-365^{\circ} \mathrm{C}\right)$ & 0.99 & 0.18 & $81.8( \pm 1.0)$ \\
\hline Fraction $3\left(365-455^{\circ} \mathrm{C}\right)$ & $\underline{0.84}$ & 0.26 & $\underline{69.0( \pm \underline{2.3})}$ \\
\hline Average & 0.90 & & $79.1( \pm 1.9)$ \\
\hline Mixture & 0.88 & 0.22 & $75.0( \pm 2.3)$ \\
\hline \multicolumn{4}{|l|}{ Nitrogen Content } \\
\hline Fraction $1\left(175-275^{\circ} \mathrm{C}\right)$ & 0.99 & 0.30 & $70.0( \pm 2.9)$ \\
\hline Fraction $2\left(275-365^{\circ} \mathrm{C}\right)$ & 1.45 & 0.60 & $58.9( \pm 2.5)$ \\
\hline Fraction $3\left(365-455^{\circ} \mathrm{C}\right)$ & $\underline{2.15}$ & 1.15 & $46.5( \pm 2.5)$ \\
\hline Average & 1.53 & & $58.4( \pm 2.6)$ \\
\hline Mixture & 1.53 & 0.65 & $57.5( \pm 2.1)$ \\
\hline \multicolumn{4}{|l|}{ H/C Atomic Ratio } \\
\hline Fraction $1\left(175-275^{\circ} \mathrm{C}\right)$ & 1.825 & 1.980 & \\
\hline Fraction $2\left(275-365^{\circ} \mathrm{C}\right)$ & 1.658 & 1.857 & \\
\hline Fraction $3\left(365-455^{\circ} \mathrm{C}\right)$ & $\underline{1.593}$ & 1.763 & \\
\hline Average & 1.692 & 1.867 & \\
\hline Mixture & 1.666 & 1.855 & \\
\hline
\end{tabular}

* The results of duplicate analysis by a commercial laboratory were averaged. 


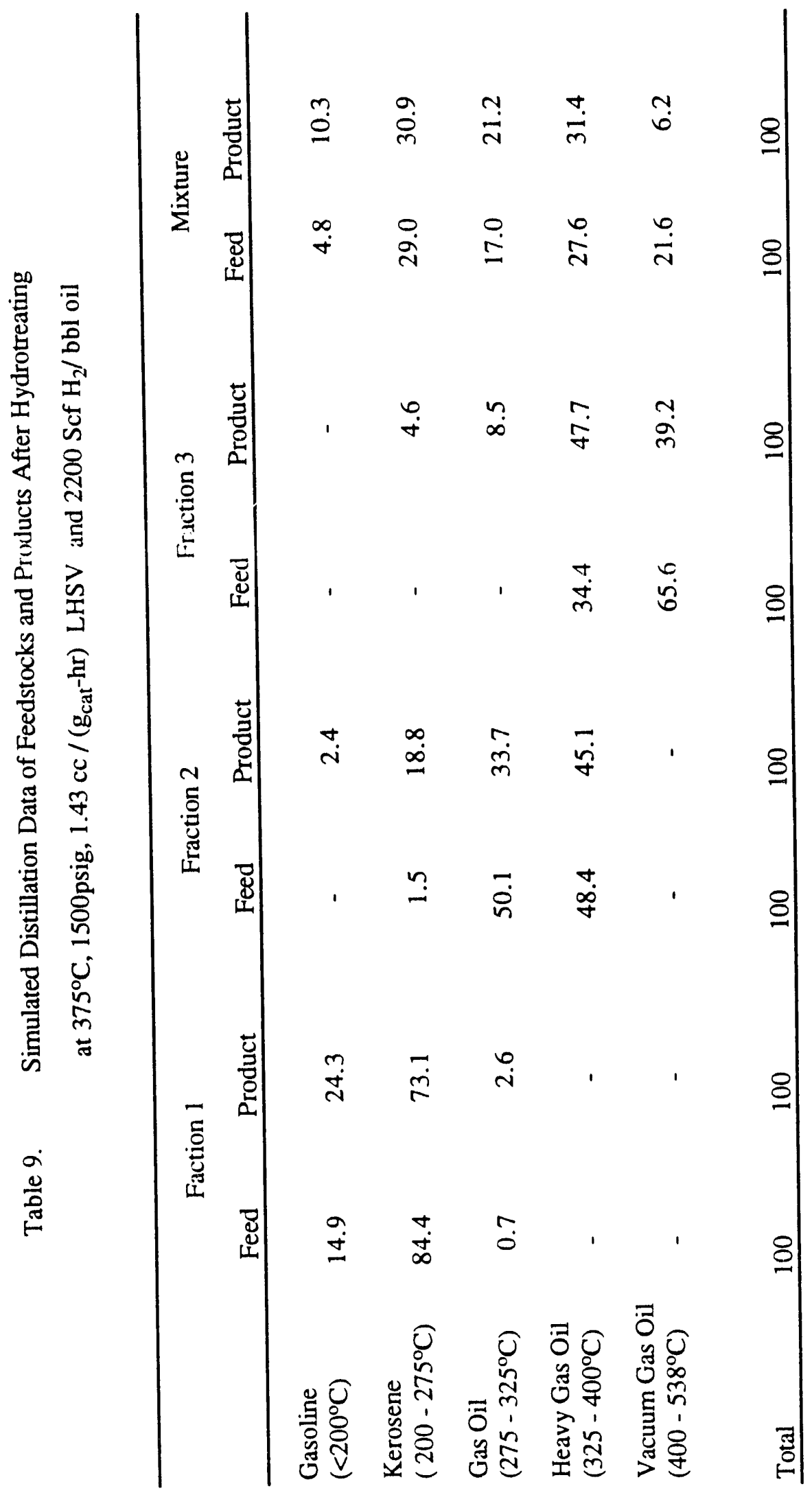


Table 10. Physical Properties of Feed and Product After Hydrotreating at $375^{\circ} \mathrm{C}$, $1500 \mathrm{psig}, 1.43 \mathrm{cc} /\left(\mathrm{g}_{\mathrm{cat}}{ }^{-\mathrm{hr}}\right) \mathrm{LHSV}$ and $2200 \mathrm{Scf}_{2} /$ bbl oil

\begin{tabular}{lcc}
\hline & Feed $\left(\mathrm{API}^{\circ}\right)$ & Product $\left(\mathrm{API}^{\circ}\right)$ \\
\hline Density $\left(60^{\circ} \mathrm{F} / 60^{\circ} \mathrm{F}, \mathrm{Sp} . \mathrm{Gr}\right)$ & & \\
Fraction 1 & $0.8188(41.3)$ & $0.7919(47.2)$ \\
Fraction 2 & $0.8705(31.0)$ & $0.8327(38.4)$ \\
Fraction 3 & $\underline{0.9330(20.2)}$ & $\underline{0.8808(29.2)}$ \\
Average & $0.8741(30.8)$ & $0.8351(38.3)$ \\
Mixture & $0.8763(30.0)$ & $0.8320(38.6)$ \\
& & \\
Viscosity $\left(25^{\circ} \mathrm{C}\right)$ & & $1.193 \mathrm{cp}$ \\
Fraction 1 & $1.573 \mathrm{cp}$ & $3.485 \mathrm{cp}$ \\
Fraction 2 & $6.888 \mathrm{cp}$ & $14.80 \mathrm{cp}$ \\
Fraction 3 & $88.99 \mathrm{cp}$ & $3.433 \mathrm{cp}$ \\
Mixture & $5.705 \mathrm{cp}$ & \\
& & \\
\hline
\end{tabular}


Table 11. Indole and Benzothiophene Contents of Feed and Products after Hydrotreating at $370^{\circ} \mathrm{C}, 1500 \mathrm{psig}, 1.43 \mathrm{cc} /\left(\mathrm{g}_{\mathrm{cat}}{ }^{-\mathrm{hr}}\right) \mathrm{LHSV}$ and $2200 \mathrm{Scf} \mathrm{H}_{2} / \mathrm{bbl}$ oil

\begin{tabular}{|c|c|c|c|}
\hline & Feed (wt\%) & Product (wt\%) & Removal Percent \\
\hline \multicolumn{4}{|l|}{ Benzothiophene } \\
\hline $\begin{array}{l}F \# 1 \\
\left(175-275^{\circ}, .\right)\end{array}$ & 5.0 & 0.19 & $96.2^{\mathrm{a}}$ \\
\hline $\begin{array}{l}F \# 2 \\
\left(275-365^{\circ} \mathrm{C}\right)\end{array}$ & 5.0 & 0.34 & 93.2 \\
\hline $\begin{array}{l}\text { F\#3 } \\
\left(365-455^{\circ} \mathrm{C}\right)\end{array}$ & $\underline{5.0}$ & 0.76 & $\underline{84.8}$ \\
\hline Average & 5.0 & & 91.4 \\
\hline Mixture & 5.0 & 0.70 & $86.0^{a}$ \\
\hline \multicolumn{4}{|l|}{ Indole } \\
\hline $\begin{array}{l}\text { F\#1 } \\
\left(175-275^{\circ} \mathrm{C}\right)\end{array}$ & 5.0 & 0.65 & $87.3^{a}( \pm 1.8)^{b}$ \\
\hline $\begin{array}{l}\text { F\#2 } \\
\left(275-365^{\circ} \mathrm{C}\right)\end{array}$ & 50 & 0.65 & $869^{a}(+13)^{b}$ \\
\hline $\begin{array}{l}F \# 3 \\
\left(365-455^{\circ} \mathrm{C}\right)\end{array}$ & 5.0 & 0.74 & $85.2( \pm 1.1)^{b}$ \\
\hline Average & 5.0 & & $\underline{86.5( \pm 1.4)}$ \\
\hline Mixture & 5.0 & 0.71 & $85.8^{\mathrm{a}}( \pm 0.3)^{\mathrm{b}}$ \\
\hline Hexadecane & 5.0 & 0.20 & 96.0 \\
\hline
\end{tabular}

$\mathrm{a}$ : These values were estimated by peak separation technique.

$\mathrm{b}$ : These values represent the range of error calculated by a confirmation run. 
Table 12. Properties of Hydropyrolysis Feedstock and Liquid Product

\begin{tabular}{|c|c|c|}
\hline Properties & $\begin{array}{c}\text { Feed } \\
\text { (Residue of Shale Oil) } \\
\end{array}$ & Product \\
\hline \multicolumn{3}{|l|}{ Elemental Analysis (wt\%) } \\
\hline Carbon & 85.57 & 84.99 \\
\hline Hydrogen & 10.82 & 11.08 \\
\hline Nitrogen & 2.06 & 1.77 \\
\hline Sulfur & 0.79 & 0.59 \\
\hline $\mathrm{H} / \mathrm{C}$, Atomic & 1.517 & 1.564 \\
\hline \multicolumn{3}{|l|}{ Simulated Distillation (wt\%) } \\
\hline$<200^{\circ} \mathrm{C}$ & - & 4.8 \\
\hline $200-275^{\circ} \mathrm{C}$ & - & 4.8 \\
\hline $275-325^{\circ} \mathrm{C}$ & - & 4.5 \\
\hline $325-400^{\circ} \mathrm{C}$ & 2.2 & 12.1 \\
\hline $400-538^{\circ} \mathrm{C}$ & 53.1 & 47.4 \\
\hline$>538^{\circ} \mathrm{C}$ & 44.7 & 26.5 \\
\hline Density, API ${ }^{\circ}$ & 13.2 & 19.4 \\
\hline Average Molecular Weight & 495 & 359 \\
\hline Specific Gravity $\left(15.6^{\circ} \mathrm{F} / 15.6^{\circ} \mathrm{F}\right)$ & 0.9779 & 0.9376 \\
\hline Viscosity, cp $\left(60^{\circ} \mathrm{C}\right)$ & 293.8 & 15.6 \\
\hline Hydrogen Consumption, scf $\mathrm{H}_{2} / \mathrm{bbl}$ oil & - & 864 \\
\hline wt \% & - & 1.48 \\
\hline
\end{tabular}


Table 13. The Composition of Gas Product Stream after Hydropyrolysis (Hydrogen Free)

\begin{tabular}{lc}
\hline Compound & $\mathrm{Wt}(\%)$ \\
\hline $\mathrm{CH}_{4}$ & 41.5 \\
$\mathrm{C}_{2} \mathrm{H}_{6}$ & 38.2 \\
$\mathrm{C}_{3} \mathrm{H}_{8}$ & 16.2 \\
$\mathrm{n}-\mathrm{C}_{4} \mathrm{H}_{10}$ & 1.5 \\
$\mathrm{i}-\mathrm{C}_{4} \mathrm{H}_{10}$ & 1.3 \\
$\mathrm{n}-\mathrm{C}_{5} \mathrm{H}_{12}$ & 0.5 \\
$\mathrm{C}_{2} \mathrm{H}_{4}$ & 0.2 \\
$\mathrm{C}_{3} \mathrm{H}_{6}$ & 0.5 \\
$1-\mathrm{C}_{4} \mathrm{H}_{8}$ & 0.2 \\
Total & 100.1 \\
\hline
\end{tabular}


Table 14. Summary of Hydrotreating Studies of HP Product

\begin{tabular}{llll}
\hline & & Log Number & \\
& HT-91-5 & HT-91-2 & HT-91-3 \\
\hline Process Conditions & & 390 & 390 \\
Temperature, ${ }^{\circ} \mathrm{C}$ & 390 & 1800 & 1800 \\
Hydrogen Pressure, Psig & 1800 & 0.71 & 0.37 \\
LHSV, cc / $\left(\mathrm{g}_{\text {cat }}\right.$-hr) & 1.43 & 2275 & 2270 \\
Gas/Oil, scf $\mathrm{H}_{2} / \mathrm{bbl} \mathrm{Oil}$ & 2303 & & \\
& & & 6.3 \\
Yield (wt\%) & & 5.2 & 93.7 \\
Gas & 2.4 & 94.8 & \\
Liquid & 97.6 & & \\
\hline
\end{tabular}


Table 15. Characteristics of Hydrotreated Liquid Products

\begin{tabular}{|c|c|c|c|}
\hline & & Log Number & \\
\hline Properties & HT-91-5 & HT-91-2 & HT-91-3 \\
\hline \multicolumn{4}{|c|}{ Elemental Analysis (wt\%) } \\
\hline Carbon & 85.41 & 85.38 & 85.99 \\
\hline Hydrogen & 12.05 & 12.19 & 12.54 \\
\hline Sulfur & 0.105 & 0.095 & 0.059 \\
\hline Nitrogen & 1.18 & 0.67 & 0.41 \\
\hline $\mathrm{H} / \mathrm{C}$, Atomic Ratio & 1.693 & 1.713 & 1.750 \\
\hline \multicolumn{4}{|c|}{ Simulated Distillation (wt\%) } \\
\hline$<200^{\circ} \mathrm{C}$ & 6.4 & 8.5 & 9.9 \\
\hline $200-275^{\circ} \mathrm{C}$ & 7.3 & 11.6 & 15.2 \\
\hline $275-325^{\circ} \mathrm{C}$ & 6.4 & 9.6 & 11.7 \\
\hline $325-400^{\circ} \mathrm{C}$ & 17.2 & 21.2 & 21.8 \\
\hline $400-538^{\circ} \mathrm{C}$ & 52.6 & 45.2 & 37.6 \\
\hline$>538^{\circ} \mathrm{C}$ & 10.1 & 3.9 & 3.8 \\
\hline Density, API $^{\circ}$ & 24.0 & 26.2 & 28.8 \\
\hline $\begin{array}{l}\text { Specific Gravity } \\
\left(15.6^{\circ} \mathrm{C} / 15.6^{\circ} \mathrm{C}\right)\end{array}$ & 0.9102 & 0.8973 & 0.8826 \\
\hline Viscosity, $\mathrm{cp}\left(60^{\circ} \mathrm{C}\right)$ & 8.9 & 8.1 & 2.2 \\
\hline \multicolumn{4}{|c|}{ Hydrogen Consumption, } \\
\hline $\mathrm{ScfH}_{2} / \mathrm{bbl}$ oil (wt\%) & $672(1.15)$ & $967(1.66)$ & $1235(2.12)$ \\
\hline
\end{tabular}


Table 16. Gas Composition of Hydrotreating Products

\begin{tabular}{lccc}
\hline & \multicolumn{3}{c}{ Log Number } \\
Compound & HT-91-5 & HT-91-2 & HT-91-3 \\
\hline $\mathrm{CH}_{4}$ & 31.7 & 29.4 & 30.3 \\
$\mathrm{C}_{2} \mathrm{H}_{6}$ & 28.6 & 25.8 & 26.0 \\
$\mathrm{C}_{3} \mathrm{H}_{8}$ & 22.3 & 21.6 & 23.5 \\
$\mathrm{n}-\mathrm{C}_{4} \mathrm{H}_{10}$ & 10.8 & 12.9 & 12.4 \\
$\mathrm{i}-\mathrm{C}_{4} \mathrm{H}_{10}$ & 2.7 & 2.6 & 2.7 \\
$\mathrm{n}-\mathrm{C}_{5} \mathrm{H}_{12}$ & 3.9 & 7.7 & 5.1 \\
& 100 & 100 & 100 \\
\hline
\end{tabular}


Table 17. Simulated Distillation and Elemental Analysis of Feedstock and Calculated Properties of a Final Product

\begin{tabular}{|c|c|c|c|}
\hline \multirow{2}{*}{\multicolumn{2}{|c|}{$\begin{array}{c}\text { Feedstock } \\
\text { (Topped Shale Oil) }\end{array}$}} & \multicolumn{2}{|c|}{ Final Product by Upgrading of Shale Oil } \\
\hline & & Lower Severities & Higher Severities \\
\hline \multicolumn{4}{|l|}{ Liquids (wt\%) } \\
\hline$<200^{\circ} \mathrm{C}$ & 0.2 & 9.7 & 13.4 \\
\hline $200-275^{\circ} \mathrm{C}$ & 11.5 & 24.3 & 28.0 \\
\hline $275-325^{\circ} \mathrm{C}$ & 17.0 & 17.3 & 16.6 \\
\hline $325-400^{\circ} \mathrm{C}$ & 30.9 & 27.9 & 20.5 \\
\hline $400-538^{\circ} \mathrm{C}$ & 33.0 & 19.5 & 20.2 \\
\hline$>538^{\circ} \mathrm{C}$ & 100 & 100 & $\frac{1.3}{100}$ \\
\hline $\begin{array}{l}\text { Atmospheric } \\
\text { Distillate }\end{array}$ & 39.3 & 51.0 & 67.8 \\
\hline $\begin{array}{l}\text { Liquid Yield } \\
(w t \%)\end{array}$ & - & 88.7 & 88.2 \\
\hline \multicolumn{4}{|c|}{ Elemental Analysis (wt\%) } \\
\hline $\mathrm{C}$ & 83.73 & 85.77 & 85.86 \\
\hline $\mathrm{H}$ & 11.53 & 12.92 & 13.25 \\
\hline $\mathrm{N}$ & 1.63 & 0.56 & 0.26 \\
\hline$S$ & 0.98 & 0.18 & 0.038 \\
\hline$O$ (by diff.) & 2.13 & 0.57 & 0.59 \\
\hline \multicolumn{4}{|c|}{ Hydrogen Consumption } \\
\hline$(\mathrm{scf} / \mathrm{bbl})$ & - & 1130 & 1376 \\
\hline
\end{tabular}


Table 18. Comparison with Conventional Upgrading Sequence

\begin{tabular}{|c|c|c|c|c|}
\hline & \multicolumn{2}{|c|}{ The proposed process } & \multicolumn{2}{|c|}{ Conventional Process ${ }^{*}$} \\
\hline Lov & Severities & High Severities & Low Severities & High Severities \\
\hline $\begin{array}{l}\text { Total Nitrogen } \\
\text { Conversion } \\
\text { (wt\%) }\end{array}$ & 65.6 & 84.0 & 65.6 & 84.0 \\
\hline $\begin{array}{l}\text { Total Hydrogen } \\
\text { Consumption } \\
\text { (Scf/bbl) }\end{array}$ & 1130 & 1376 & 1040 & 1500 \\
\hline $\begin{array}{l}\text { Yield of Distillate } \\
\left(<350^{\circ} \mathrm{C}\right)\end{array}$ & NA & 67.8 & NA & 43 \\
\hline $\begin{array}{l}\text { Distillate }\left(<350^{\circ} \mathrm{C}\right) \\
\text { in Raw Shale Oil }\end{array}$ & NA & 39.3 & $\mathrm{NA}$ & 29 \\
\hline $\begin{array}{l}\mathrm{H} / \mathrm{C} \text { Ratio of } \\
\text { Hydrotreated }\end{array}$ & & & & \\
\hline Distillate $\left(<365^{\circ} \mathrm{C}\right)$ & $\mathrm{NA}$ & 1.94 & NA & NA \\
\hline & $\mathrm{NA}=$ not & available & & \\
\hline
\end{tabular}

* Calculated from data in reference 6. 


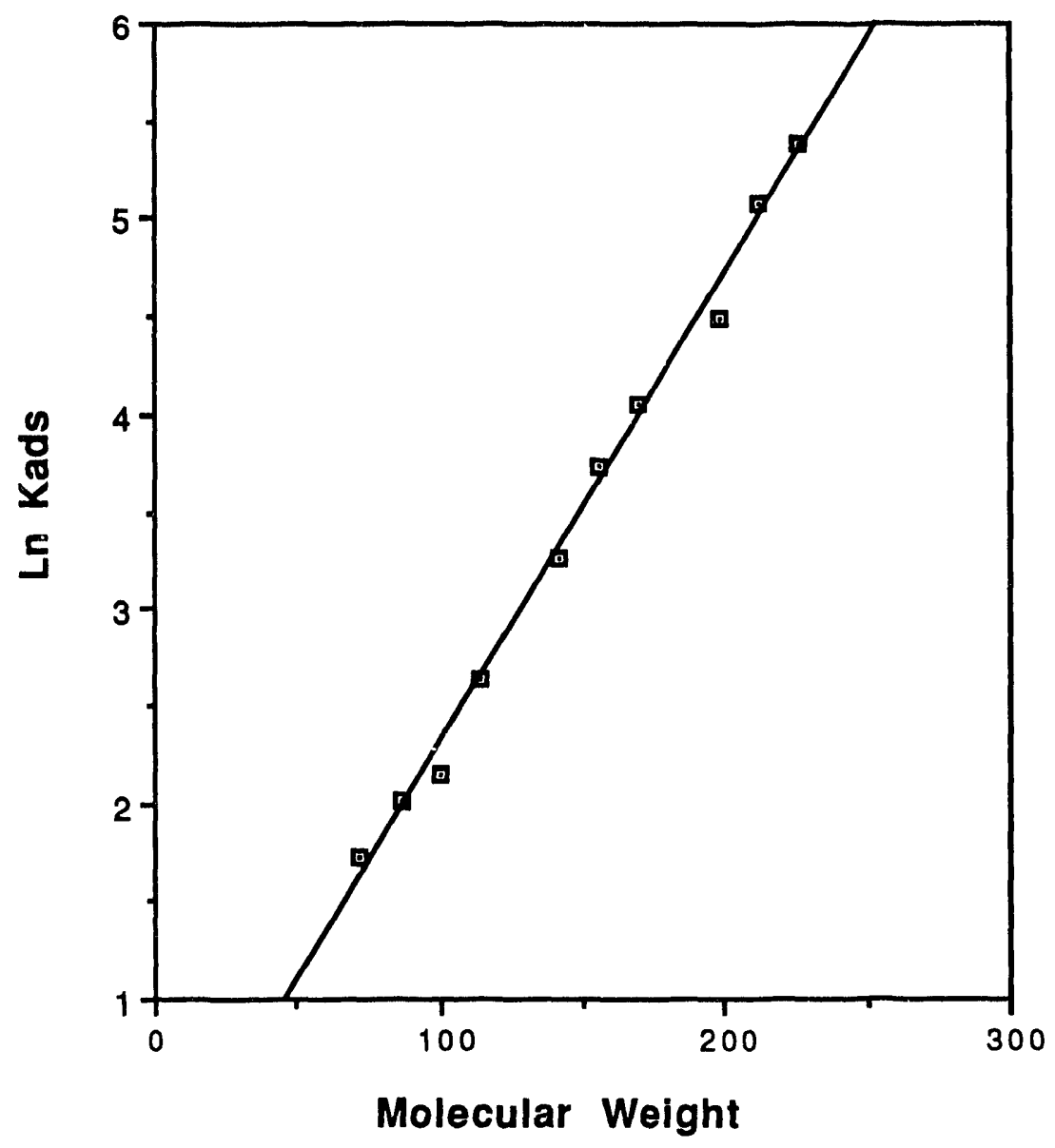

Figure 1. Adsorption Equilibrium Constants of Paraffins 

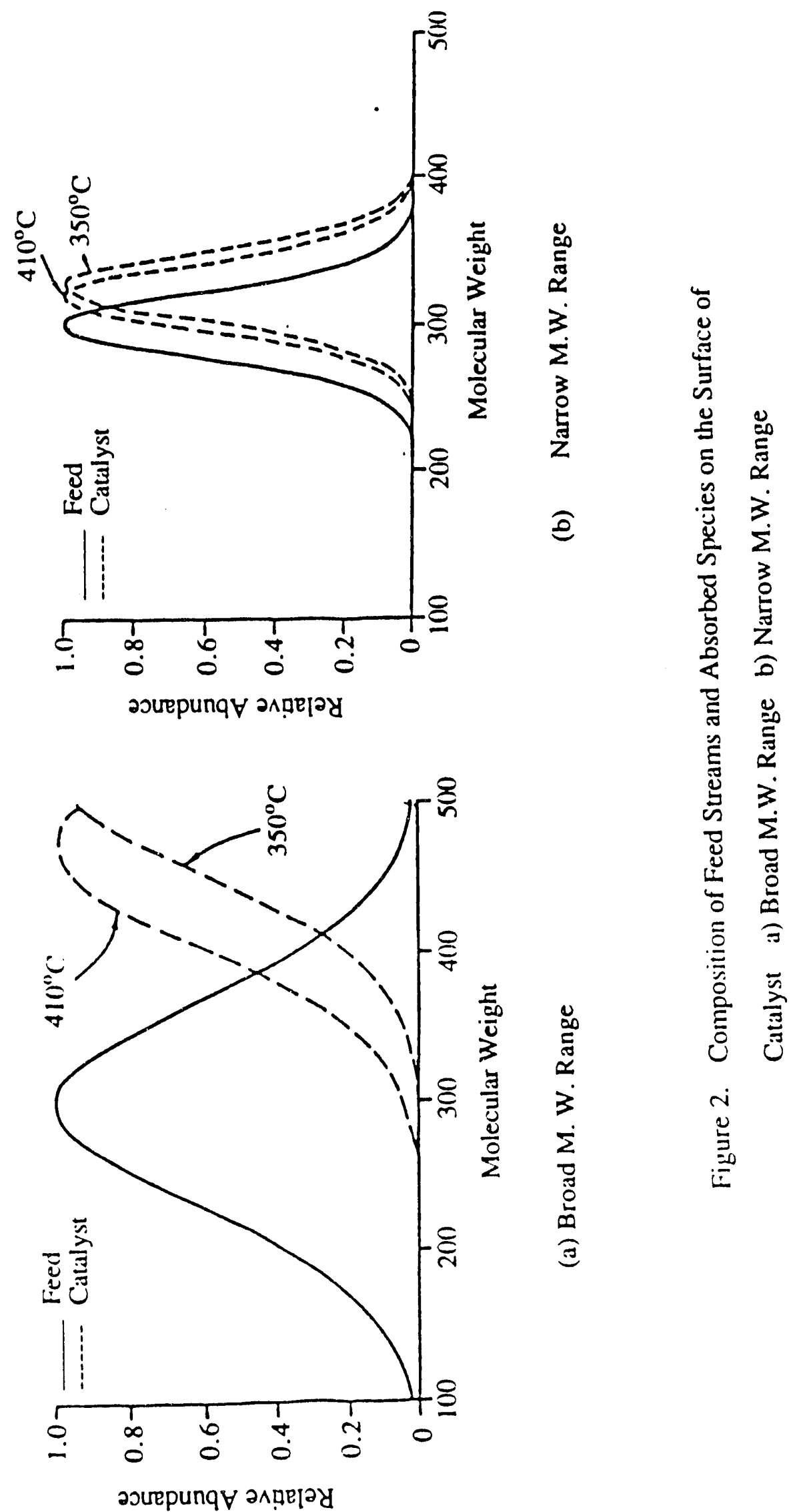


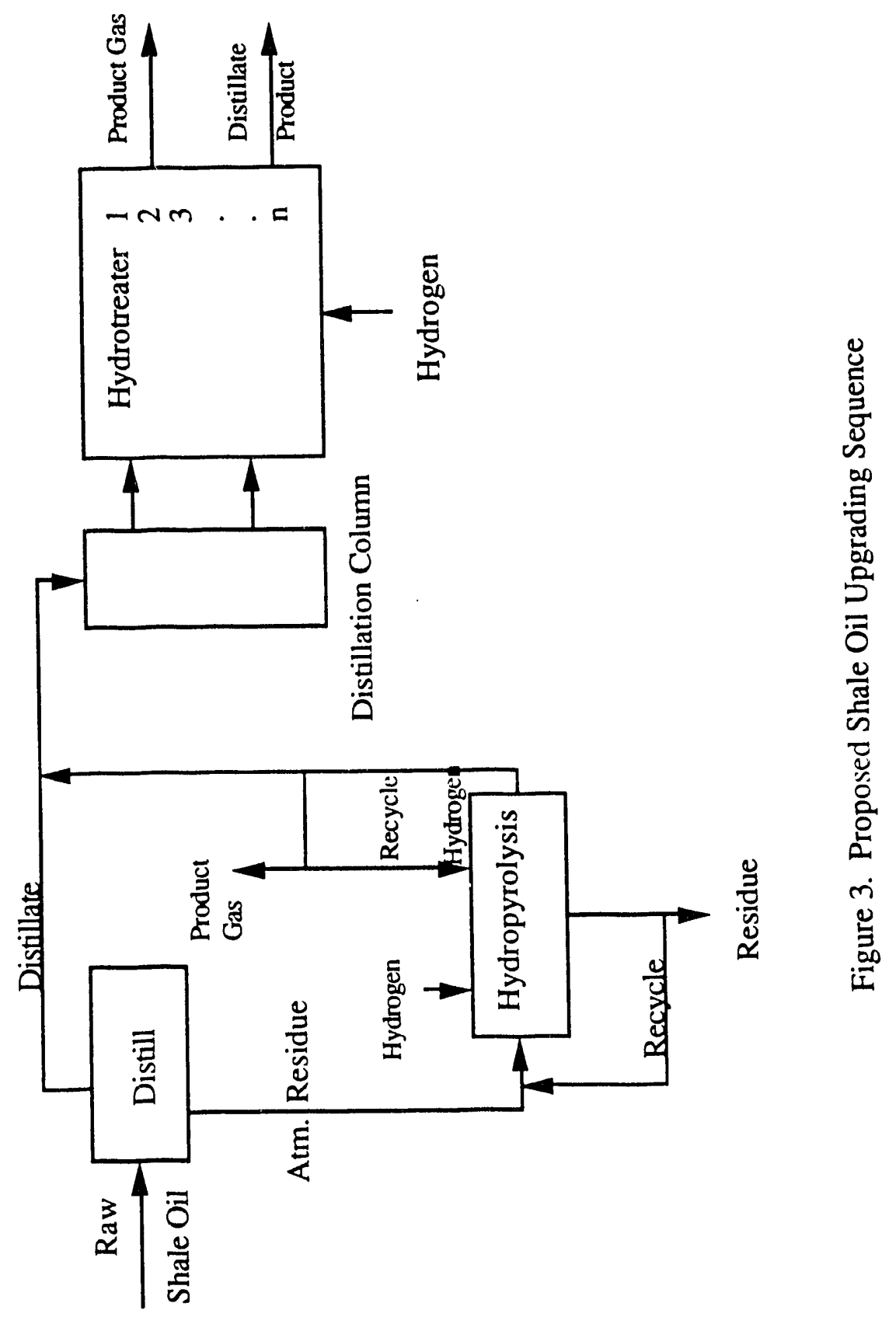




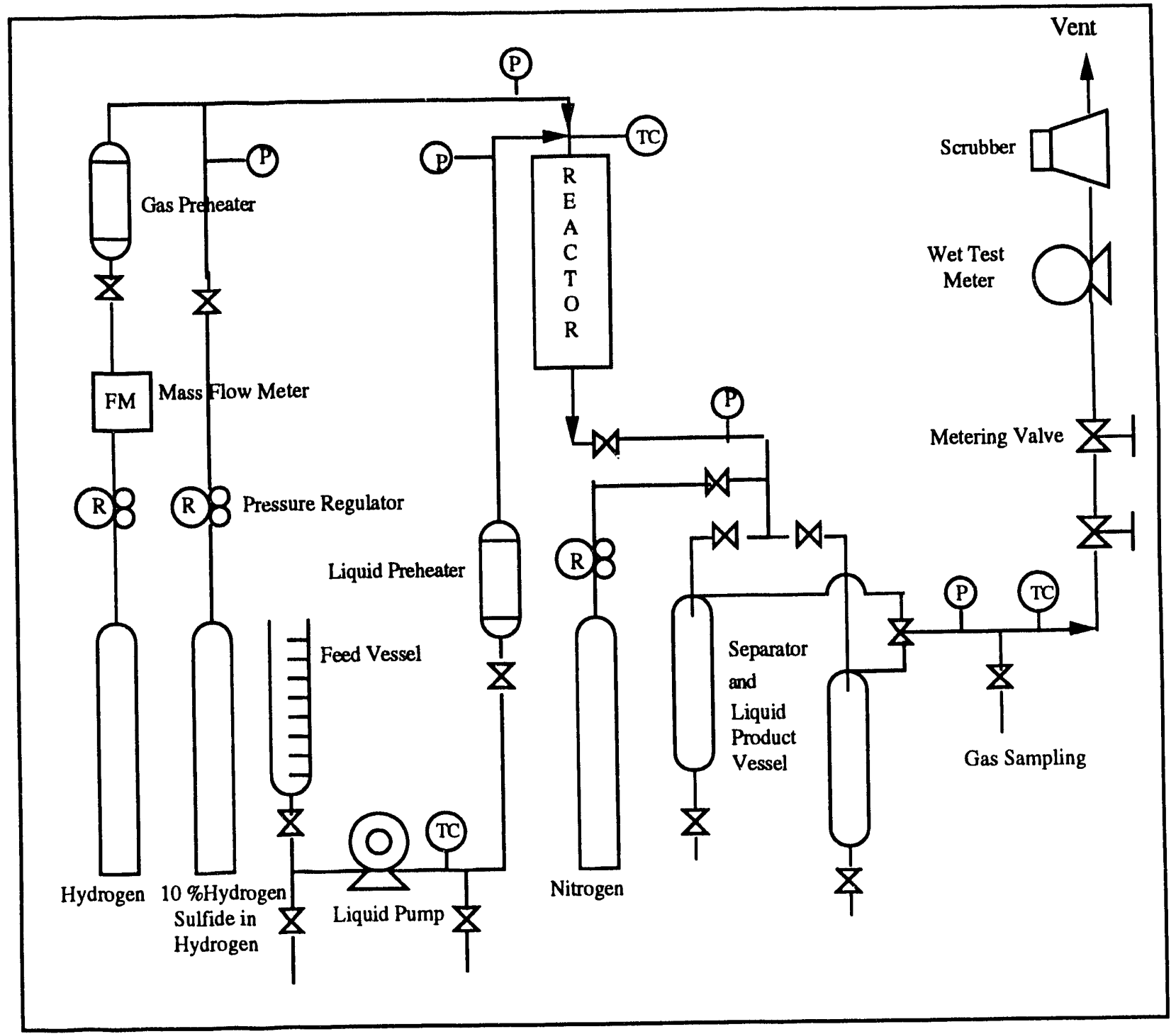

Figure 4. Schematic Diagram of Hydrotreating Unit 


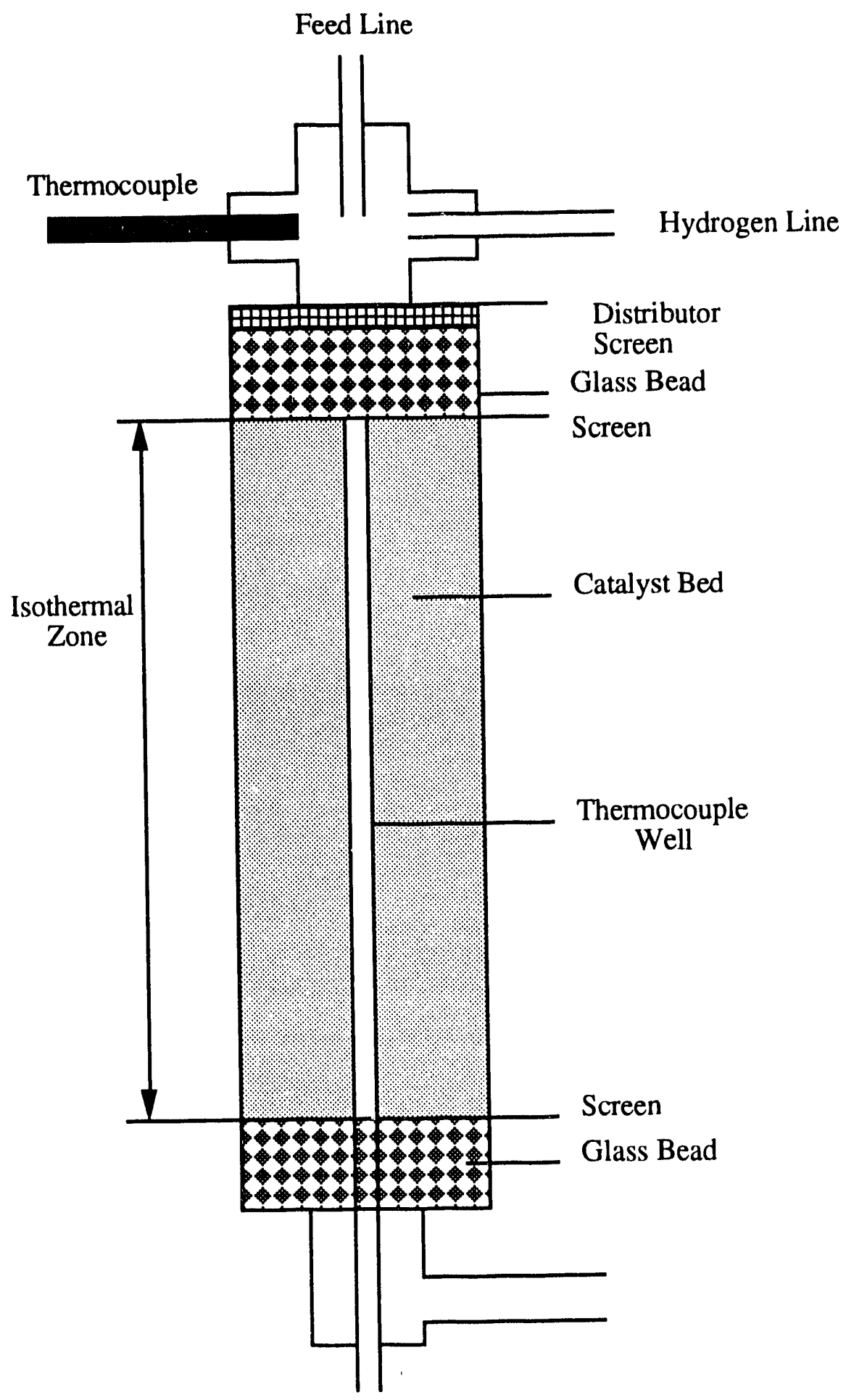

Figure 5. Schematic Diagram of Trickle Bed Reactor 


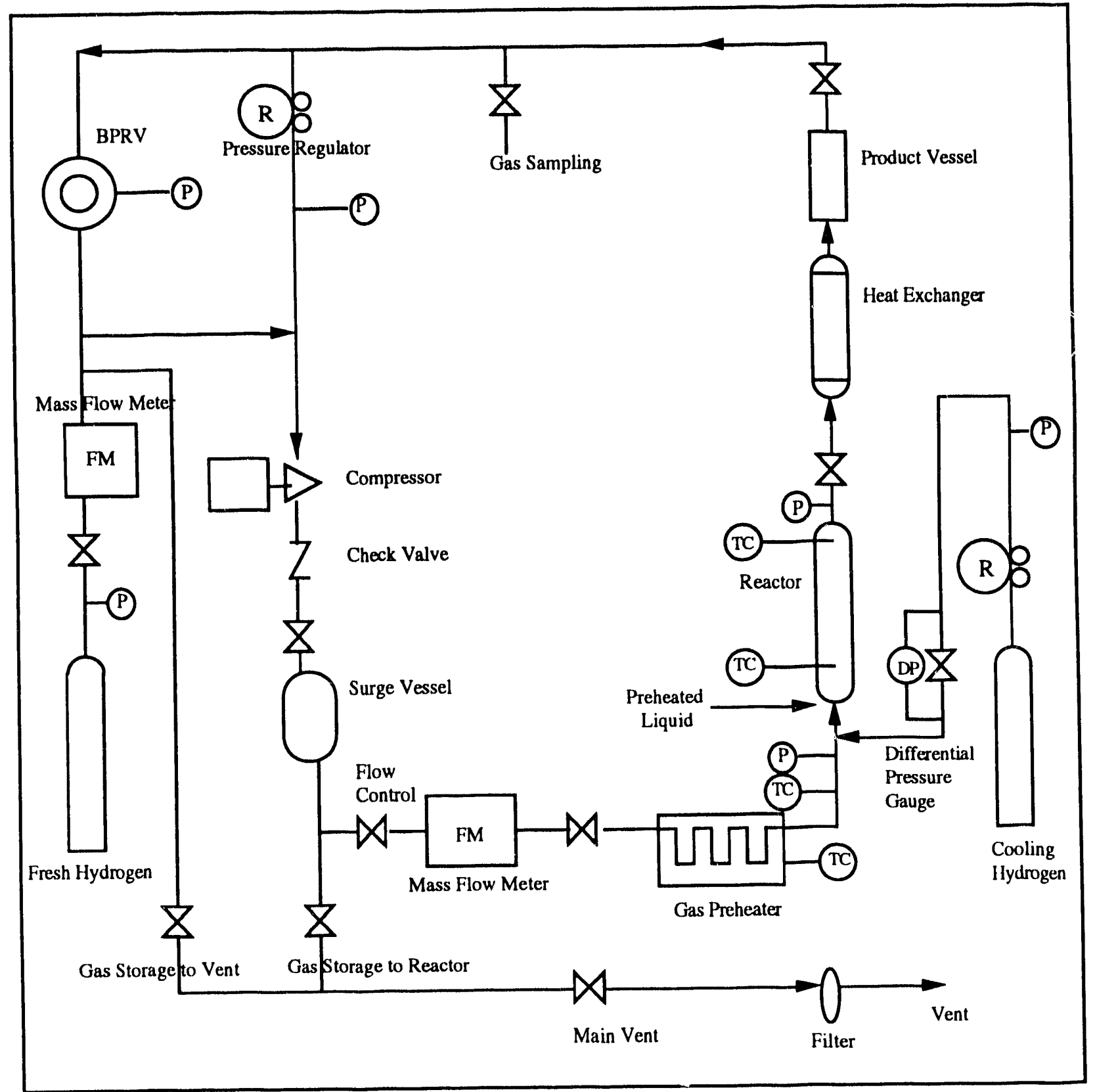

Figure 6. Schematic Diagram of Gas Handling System of Hydropyrolysis Unit 


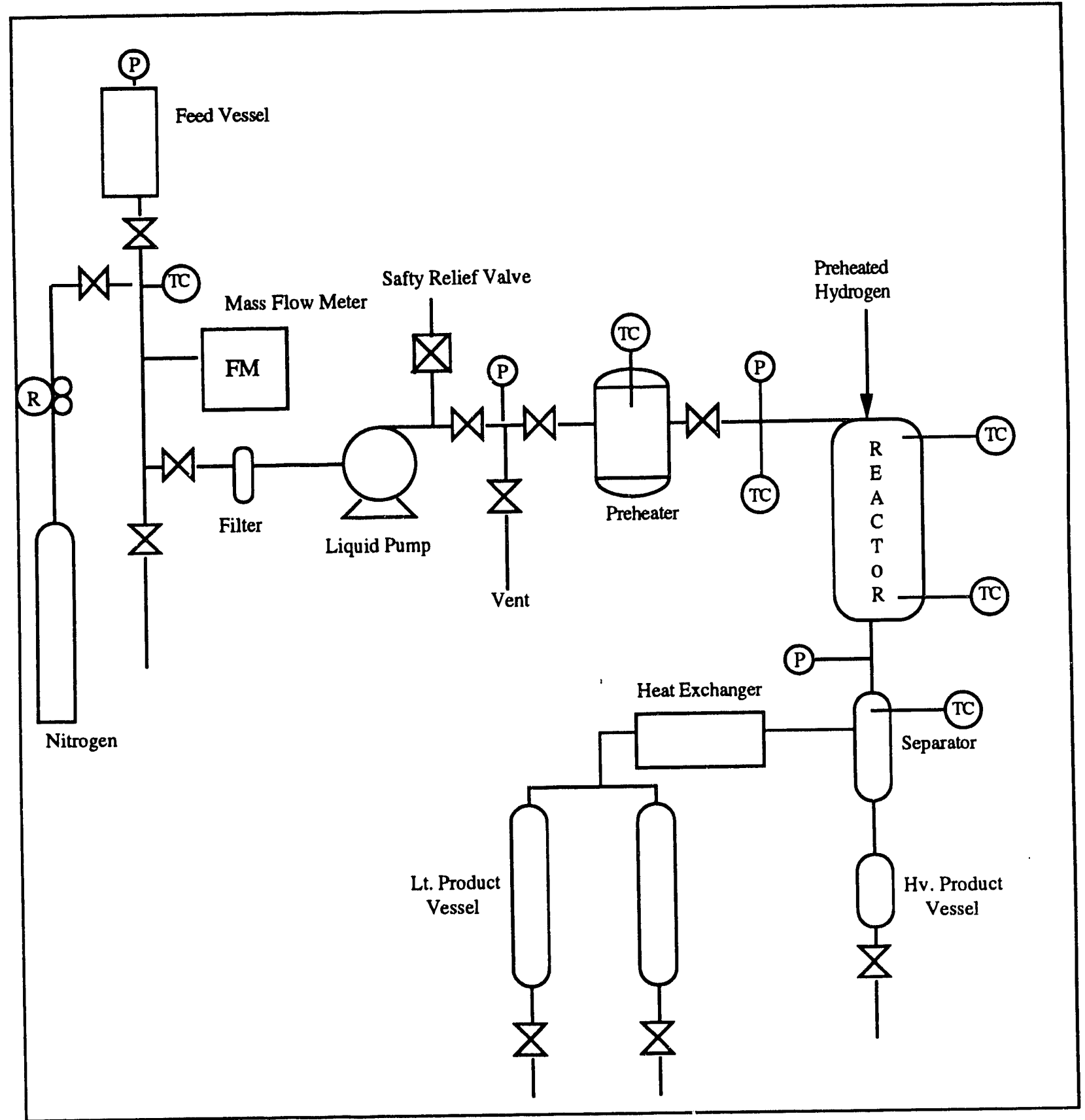

Figure 7. Schematic Diagram of Liquid Handling System of Hydropyrolysis Unit 
Method
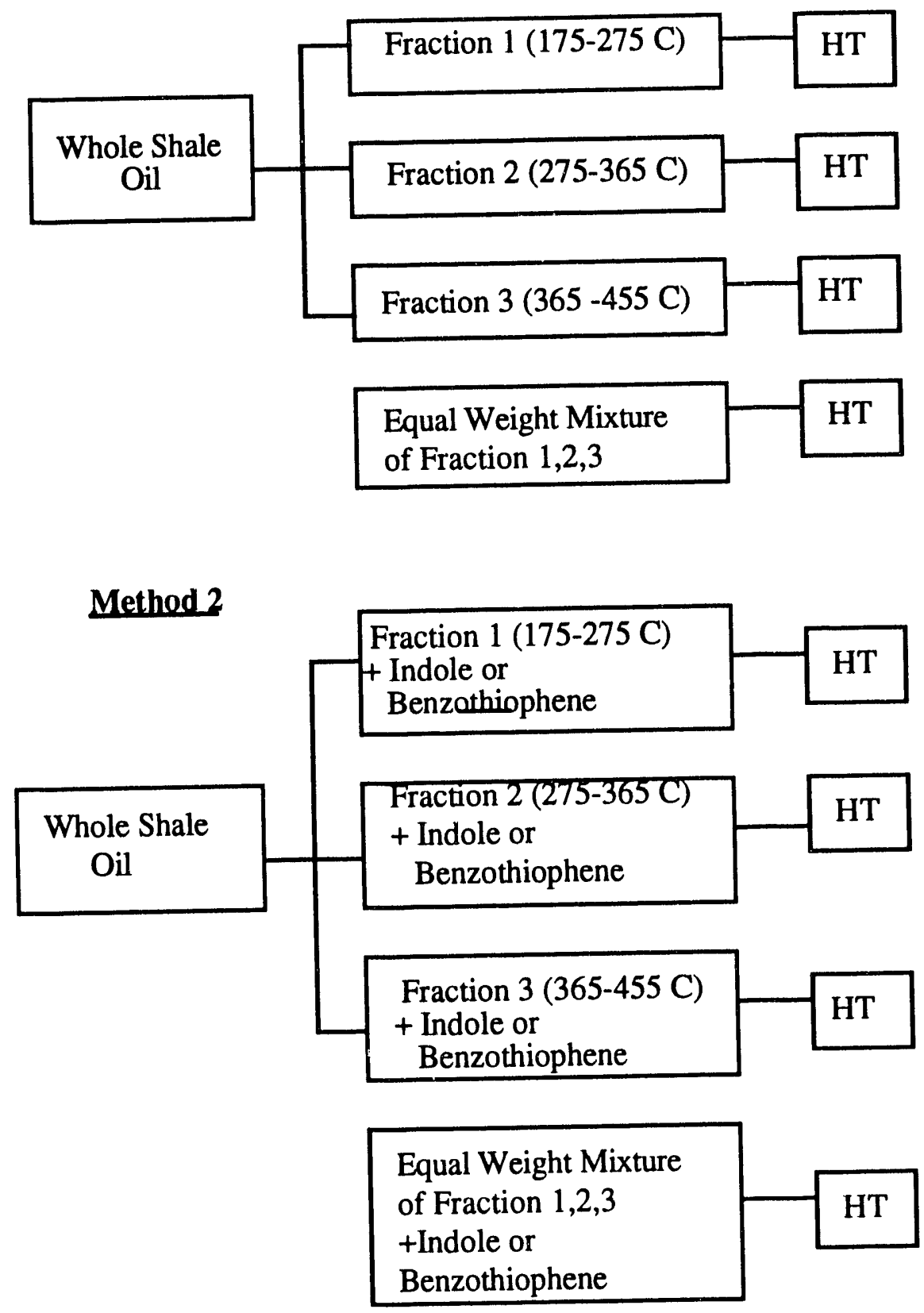

Figure 8. Experimental Works for Confirming Competitive Adsorption Effects 


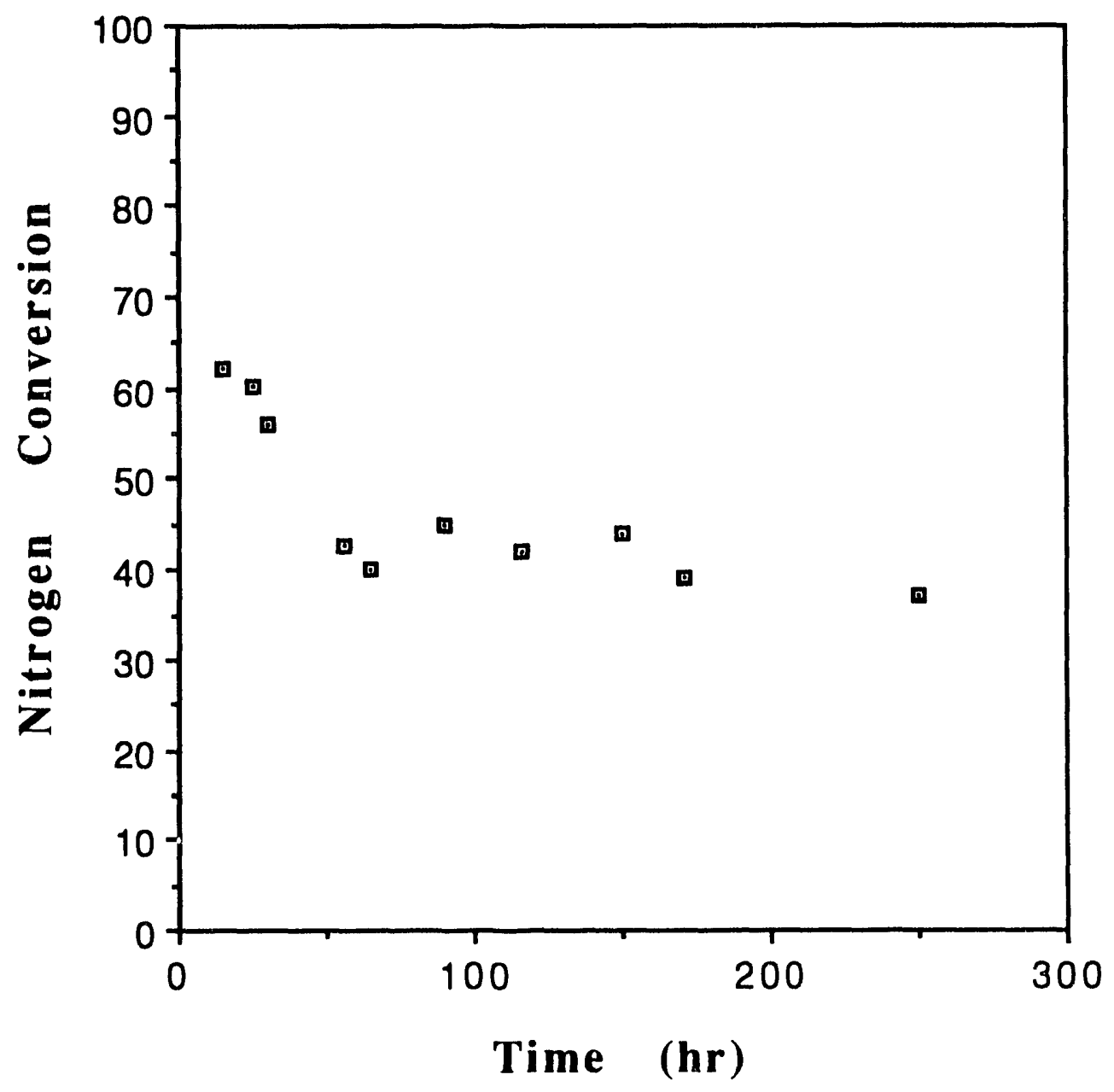

Figure 9. Nitrogen Conversion Versus Total Reaction Time for Investigating the Catalyst Deactivation.

Reaction Condition: $375^{\circ} \mathrm{C}, 1500 \mathrm{psig}, 1.43 \mathrm{cc} /\left(\mathrm{g}_{\mathrm{cat}}\right.$-hr) LHSV, and $2200 \mathrm{scf}_{2} / \mathrm{bbl}$ oil using Whole Shale Oil. 


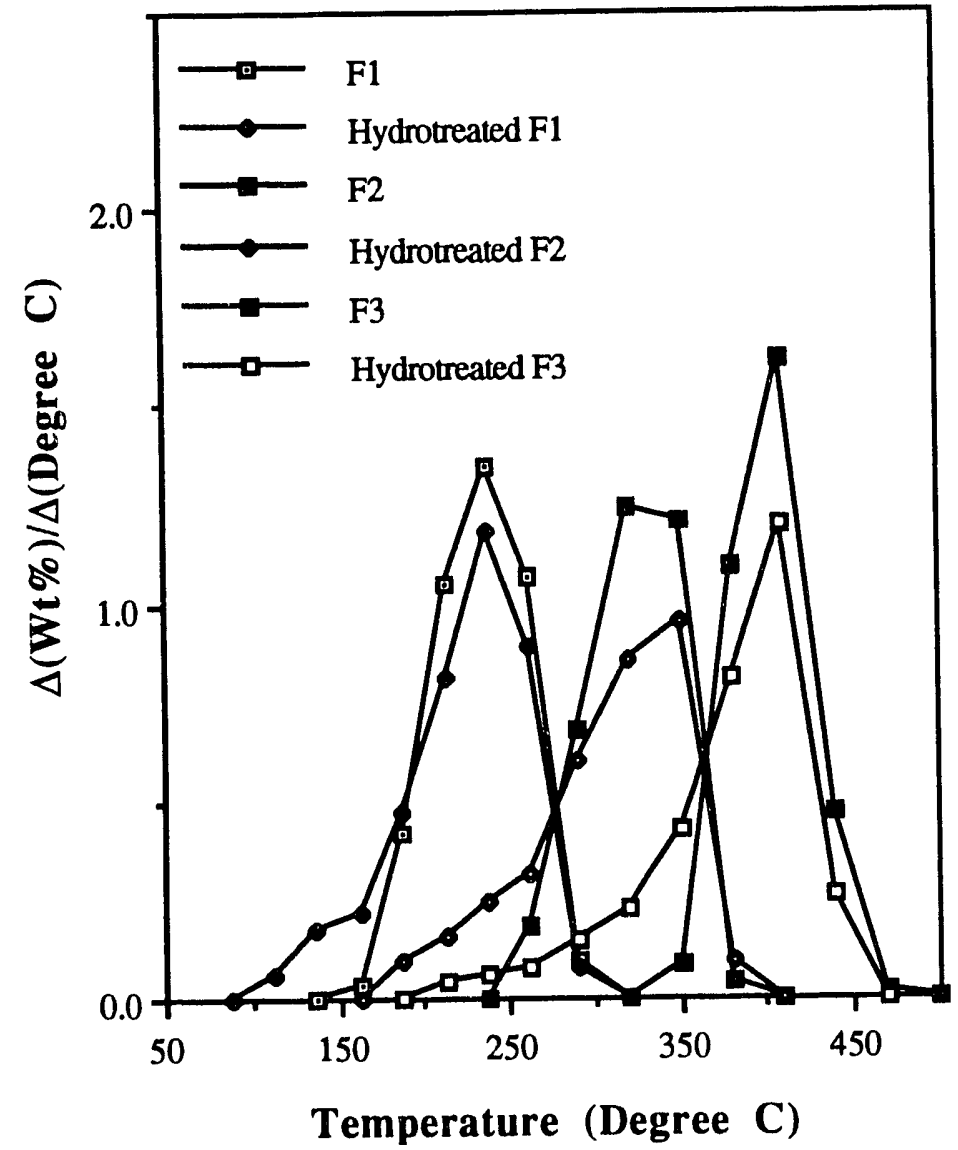

Figure 10. Simulated Distillation of Three Distillates and Three Distillates Hydrotreated at $375^{\circ} \mathrm{C}, 1.43 \mathrm{cc} /\left(\mathrm{g}_{\mathrm{cat}}{ }^{-\mathrm{hr}}\right.$ ) LHSV, $1500 \mathrm{psig}$, and $2200 \mathrm{Scf}_{2} / \mathrm{bbl}$ oil 


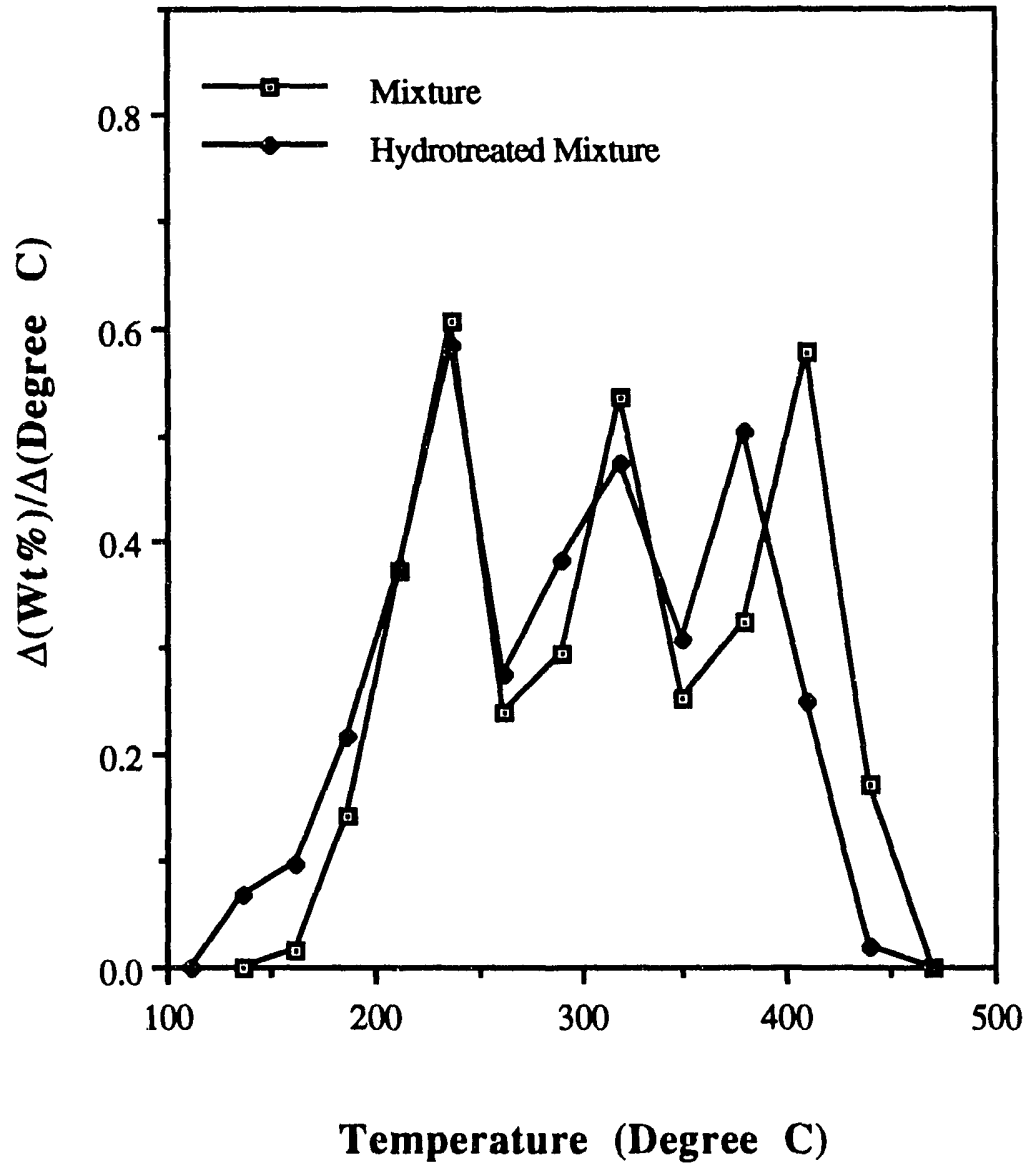

Figure 11. Simulated Distillation of Mixture and Mixture Hydrotreated at $375^{\circ} \mathrm{C}$, $1.43 \mathrm{cc} /\left(\mathrm{gcat}^{-} \mathrm{hr}\right)$ LHSV, $1500 \mathrm{psig}$, and $2200 \mathrm{Scf}_{2} / \mathrm{bbl}$ oil 


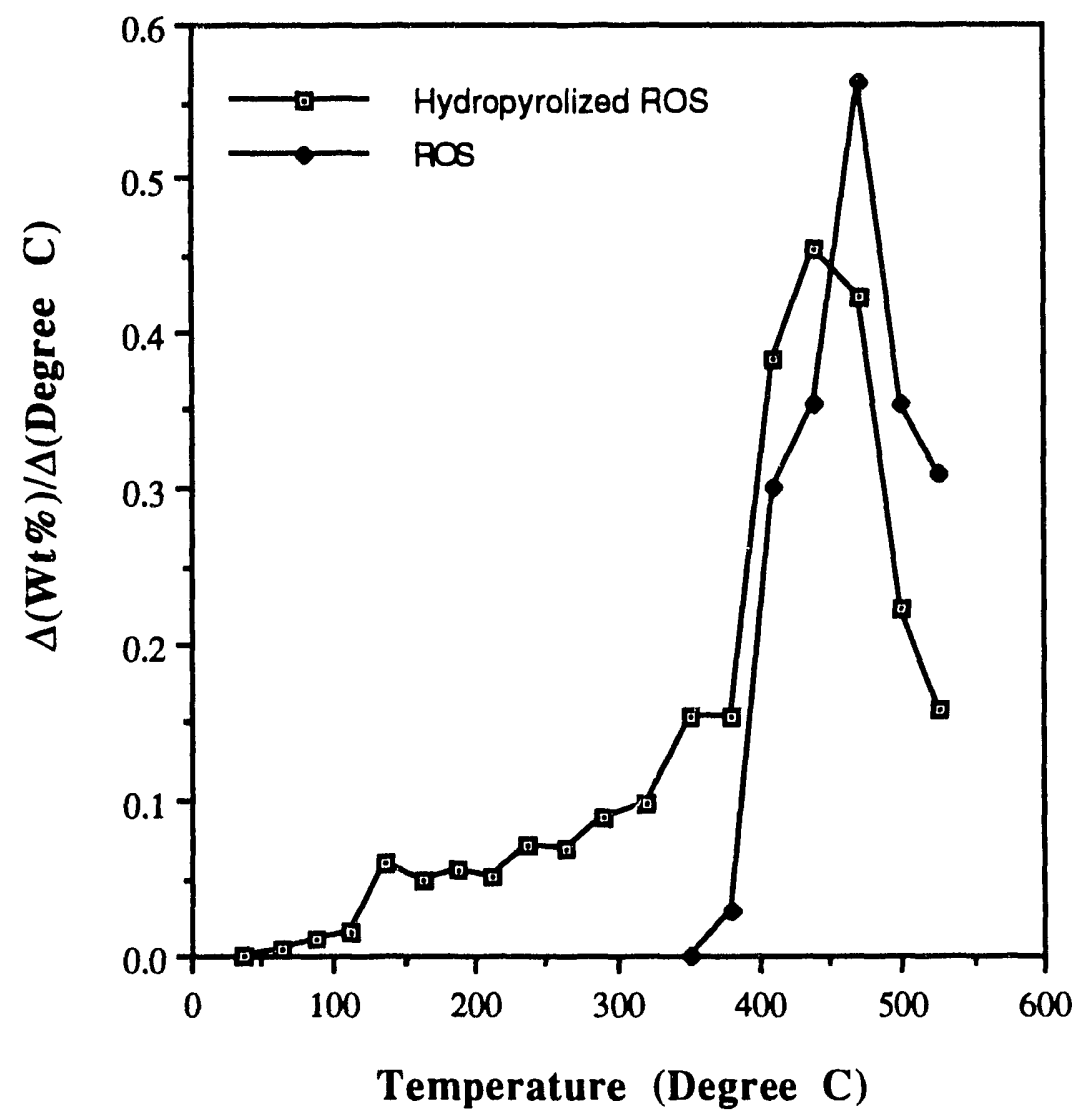

Figure 12. Simulated Distillation of Residue of Shale Oil and Hydropyrolyzed Product Reaction Conditions : $510^{\circ} \mathrm{C}, 1800 \mathrm{psig}, 1.71 \mathrm{sec}$ for Gas Residence Time $1.08 \mathrm{Feed} / \mathrm{Gas}$ Ratio (ROS : Residue of Shale Oil) 


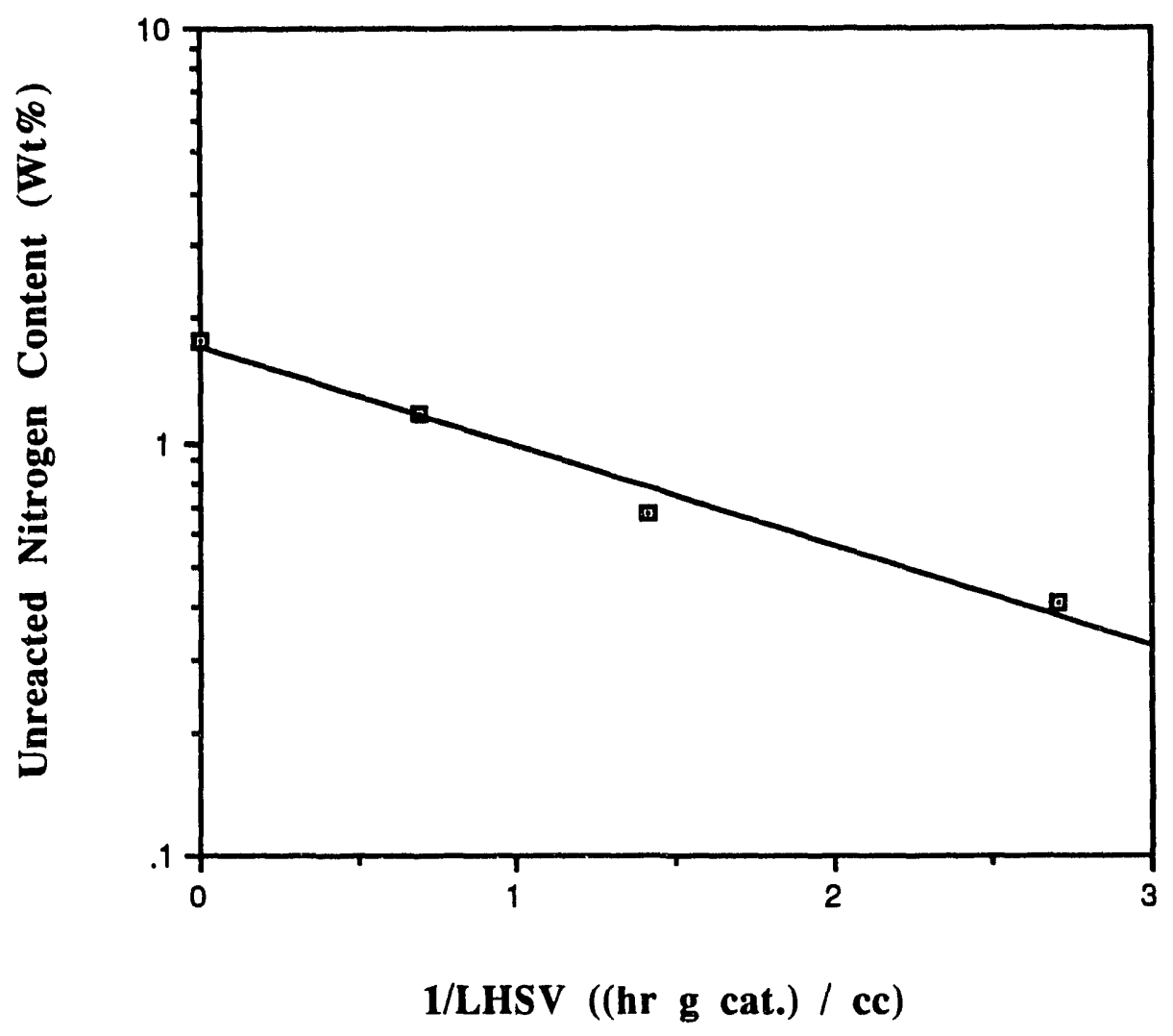

Figure 13. HDN Kinetics of HP product about the Pseudo First Order Reaction 


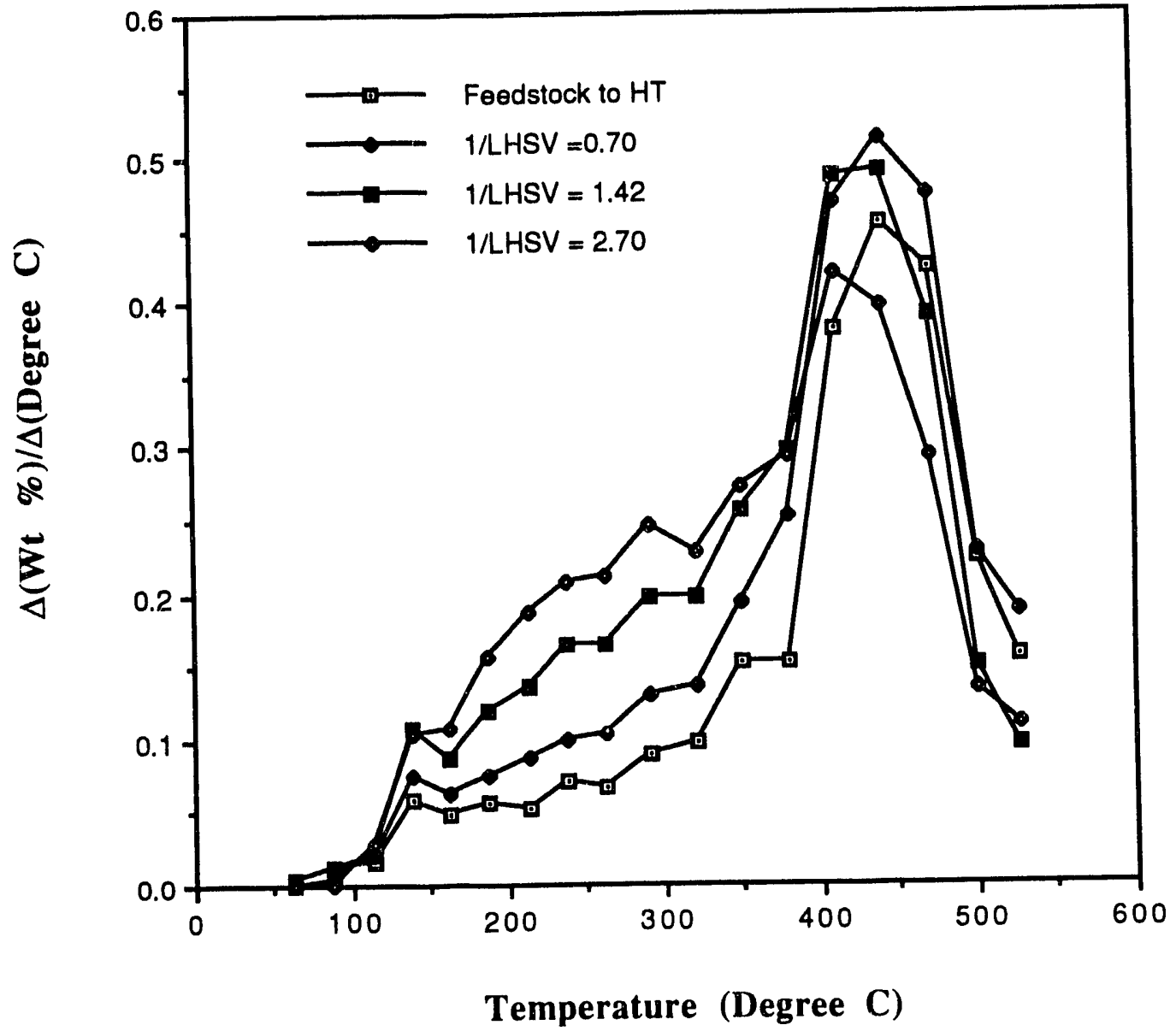

Figure 14. Simulated Distillation of Feed and Product of Hydrotreating at Various Reaction Times 


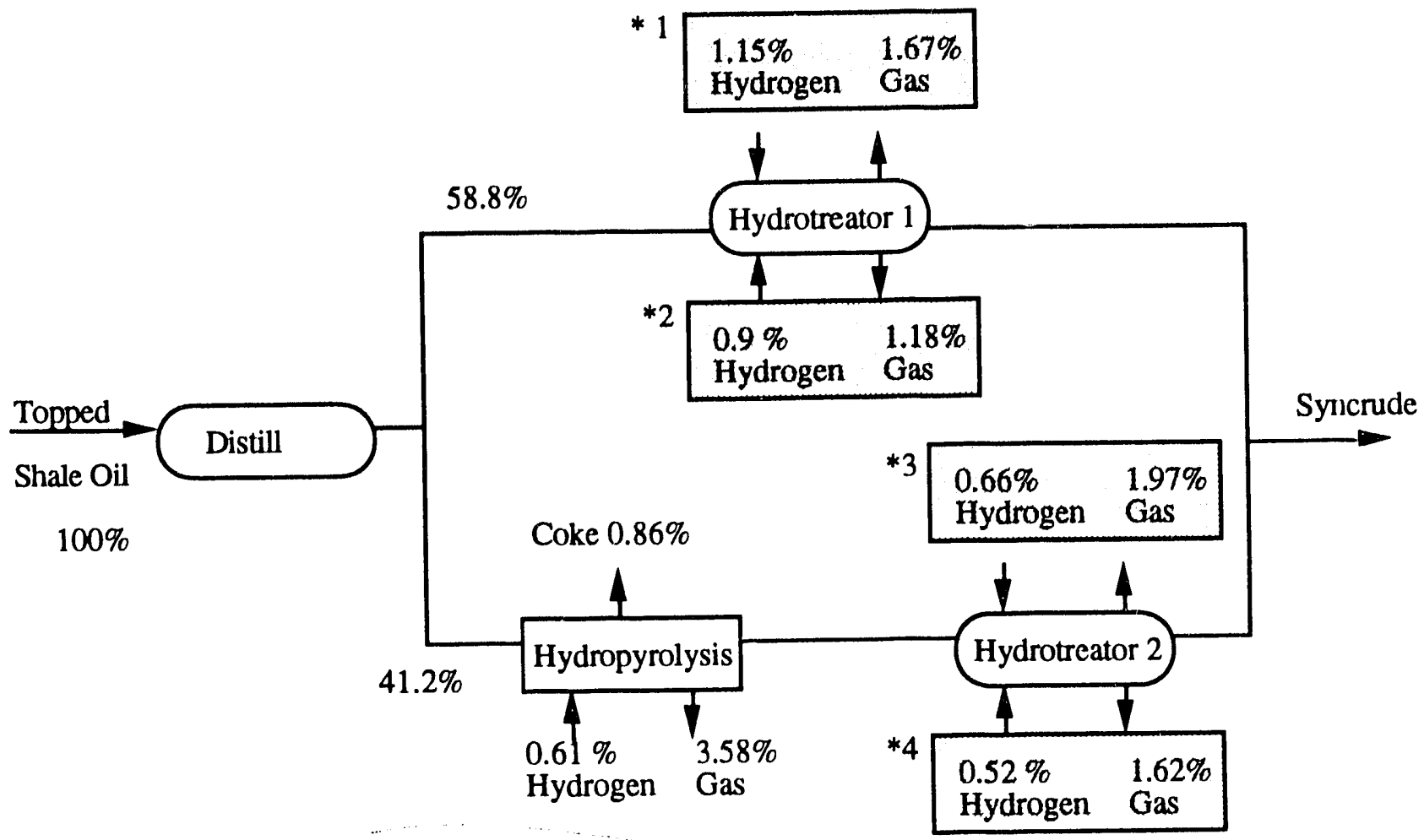

Two sets of experimental conditions for hydrotreating

*1 High severities : $400 \mathrm{C}, 1800 \mathrm{psig}, 0.70$ LHSV

* 3 High severities : 390 C, 1800 psig, 0.37 LHSV

* 2 Low severities : 375 C, 1800psig, 1.43 LHSV

* 4 Low severities : 390 C, 1800psig, 0.71 LHSV

Figure 15. New Upgrading Sequence for Shale Oil 

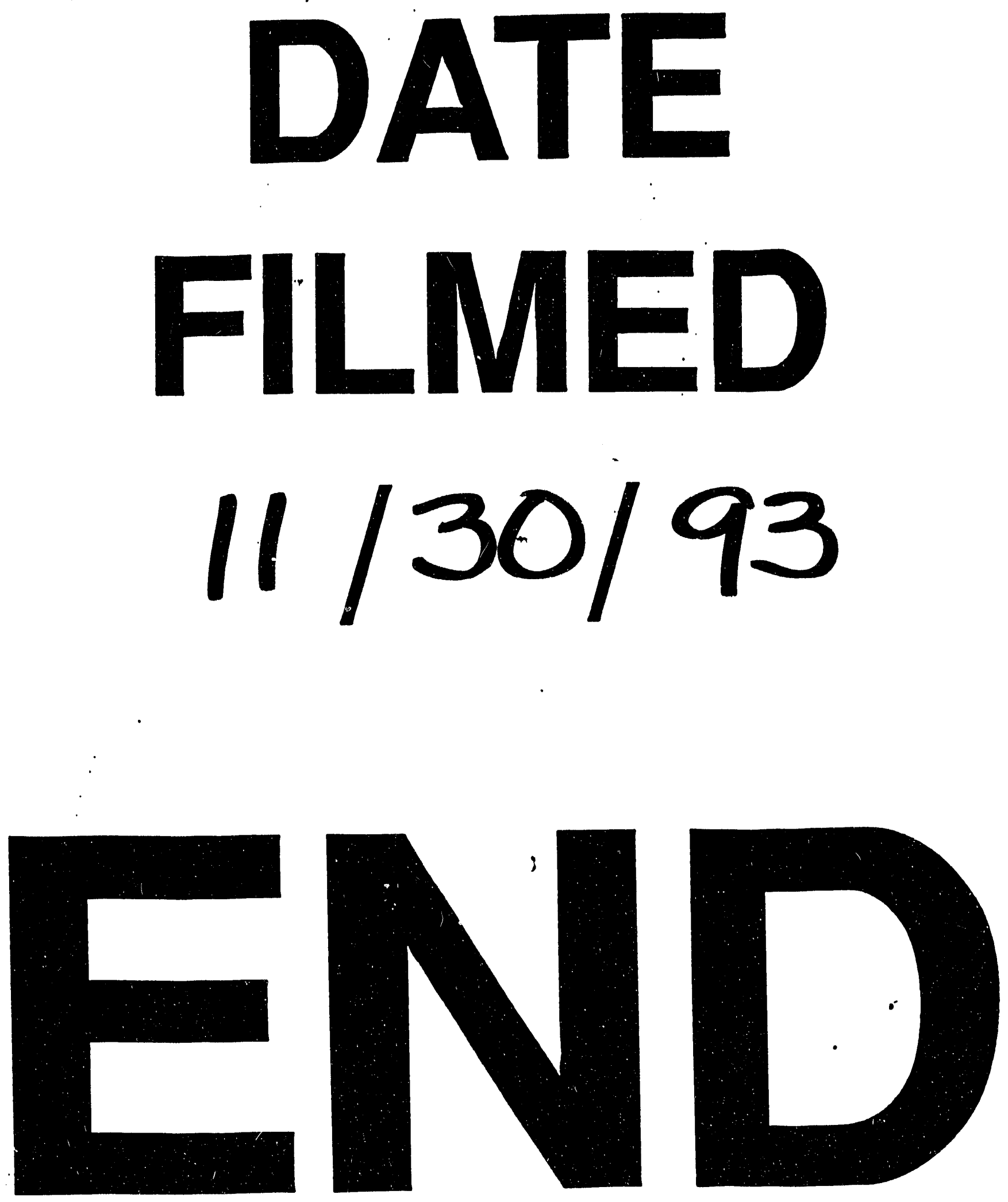
